\title{
Development of a cloud microphysical model and parameterizations to describe the effect of $\mathrm{CCN}$ on warm cloud
}

\author{
N. Kuba ${ }^{1}$ and Y. Fujiyoshi' ${ }^{2}$ \\ ${ }^{1}$ Frontier Research Center for Global Change (FRCGC), Japan Agency for Marin-Earth Science and Technology \\ (JAMSTEC), Yokohama, Japan \\ ${ }^{2}$ Frontier Research Center for Global Change (FRCGC), Japan Agency for Marin-Earth Science and Technology \\ (JAMSTEC)/Inst. Low. Temp. Sci., Hokkaido Univ., Sapporo, Japan
}

Received: 30 November 2005 - Published in Atmos. Chem. Phys. Discuss.: 21 February 2006

Revised: 16 May 2006 - Accepted: 15 June 2006 - Published: 10 July 2006

\begin{abstract}
First, a hybrid cloud microphysical model was developed that incorporates both Lagrangian and Eulerian frameworks to study quantitatively the effect of cloud condensation nuclei $(\mathrm{CCN})$ on the precipitation of warm clouds. A parcel model and a grid model comprise the cloud model. The condensation growth of $\mathrm{CCN}$ in each parcel is estimated in a Lagrangian framework. Changes in cloud droplet size distribution arising from condensation and coalescence are calculated on grid points using a two-moment bin method in a semi-Lagrangian framework. Sedimentation and advection are estimated in the Eulerian framework between grid points. Results from the cloud model show that an increase in the number of $\mathrm{CCN}$ affects both the amount and the area of precipitation. Additionally, results from the hybrid microphysical model and Kessler's parameterization were compared.
\end{abstract}

Second, new parameterizations were developed that estimate the number and size distribution of cloud droplets given the updraft velocity and the number of CCN. The parameterizations were derived from the results of numerous numerical experiments that used the cloud microphysical parcel model. The input information of $\mathrm{CCN}$ for these parameterizations is only several values of $\mathrm{CCN}$ spectrum (they are given by $\mathrm{CCN}$ counter for example). It is more convenient than conventional parameterizations those need values concerned with $\mathrm{CCN}$ spectrum, $C$ and $k$ in the equation of $\mathrm{N}=\mathrm{CS}^{k}$, or, breadth, total number and median radius, for example. The new parameterizations' predictions of initial cloud droplet size distribution for the bin method were verified by using the aforesaid hybrid microphysical model. The newly developed parameterizations will save computing time, and can effectively approximate components of cloud

Correspondence to: N. Kuba

(kuba@jamstec.go.jp) microphysics in a non-hydrostatic cloud model. The parameterizations are useful not only in the bin method in the regional cloud-resolving model but also both for a two-moment bulk microphysical model and for a global model. The effects of sea salt, sulfate, and organic carbon particles were also studied with these parameterizations and global model.

\section{Introduction}

Accurate representation of the effect of aerosols on precipitation and on the optical properties of clouds is a key to improving climate models. Previous studies have shown that variations in cloud nuclei are primarily responsible for variations in cloud droplet concentrations and colloidal stability (Twomey and Squires, 1959; Twomey and Warner, 1967; Harshvardhan et al., 2002). Differences in cloud microstructure cause differences in optical properties, precipitation efficiency, and cloud lifetime (Twomey, 1974; Albrecht et al., 1995). For example, an increase in the number of aerosol particles suppresses precipitation (Rosenfeld, 1999, 2000; Andreae et al., 2004; Givati and Rosenfeld, 2004). It is therefore desirable to use cloud microphysical models that can simulate the effects of cloud condensation nuclei $(\mathrm{CCN})$ on the cloud microstructure in climate or cloud models.

Many studies have used detailed microphysical models (Clark, 1973; Takahashi, 1976; Hall, 1980; Reisin et al., 1996; Khain et al., 1999). Vertical intervals between grid points in those studies exceeded $100 \mathrm{~m}$, but grid point supersaturation values were used to estimate $\mathrm{CCN}$ nucleation. The number concentration of cloud droplets significantly influences the radiative properties and precipitation efficiency of clouds and depends on the $\mathrm{CCN}$ spectrum and maximum

Published by Copernicus GmbH on behalf of the European Geosciences Union. 
value of supersaturation near the cloud base. Supersaturation changes very rapidly near the cloud base, so its maximum value cannot be estimated from values on grid points with intervals exceeding tens of meters. Furthermore, supersaturation is affected by updraft velocity and by the number of activated nuclei. It is therefore advantageous to calculate $\mathrm{CCN}$ growth by condensation in a Lagrangian framework to determine if and when each nucleus is activated.

Chen and Lamb (1999) used a detailed microphysical and chemical cloud model (Chen and Lamb 1994) to simulate orographic cloud formation. A Lagrangian approach using 15 parcels to represent 15 vertical layers was used to examine microphysical processes. The results agreed with observations, but it is difficult to apply the technique to different situations. Khairoutdinov and Kogan (1999) developed a large eddy simulation model that includes an explicit microphysics scheme. Their grid point vertical interval $(25 \mathrm{~m})$ is smaller than previous studies but not small enough to allow an accurate estimate of maximum supersaturation near the cloud base. Furthermore, their CCN classification cannot accurately estimate the number of activated CCN (number of cloud droplets).

Rainfall amounts and precipitation area are affected by raindrop fall velocity, which has a wide distribution (from $10 \mathrm{~cm} \mathrm{~s}^{-1}$ to $10 \mathrm{~m} \mathrm{~s}^{-1}$ ). Differences in fall velocity cannot be neglected if precipitation is to be simulated precisely, yet conventional bulk models put all rainwater in only one category. Cotton et al. (2003) showed that the Colorado State University Regional Atmospheric Modeling System (RAMS), which has a bulk microphysical model but simulates sedimentation by emulating a full-bin model, can get the results agreeing with the results from a full bin resolving microphysics model in a large eddy simulation (LES). It shows that the difference in fall velocity caused by the difference in the size of droplets is important. A bin model can resolve differences not only in fall velocity but also in collection efficiency more accurately according to the resolution of the bin framework.

The microphysical model in this study is based on the twomoment bin method developed by Chen and Lamb (1994). In addition, a Lagrangian framework is used to estimate the $\mathrm{CCN}$ activation and to give the initial cloud droplet size distribution for the bin model. The model estimates both the condensational growth of each cloud condensation nucleus and the time change of supersaturation in a Lagrangian framework. Therefore, the number concentration of activated $\mathrm{CCN}$ and the size distribution of cloud droplets can be estimated accurately. As a result, the relationship between $\mathrm{CCN}$ and precipitation efficiency in warm clouds can be studied precisely.

The model developed in this study can also be used to verify and improve the microphysical bulk model. It is difficult, however, to install this hybrid cloud microphysical model with both Lagrangian and Eulerian frameworks into a nonhydrostatic 3-D cloud model. It is also difficult to input a full CCN spectrum into a simulation. Therefore, parameterizations were developed that predict the initial cloud droplet size distribution for a cloud microphysical model that uses the bin method. Input $\mathrm{CCN}$ data for the parameterizations can be simplified if the most influential factor can be found. The impacts on precipitation of small particle $\mathrm{CCN}$, large particle $\mathrm{CCN}$, and giant particle $\mathrm{CCN}$ were estimated systematically using the hybrid cloud microphysical model. The parameterizations developed were then verified using the hybrid cloud microphysical model. The parameterizations thus developed are useful not only for the bin method in regional cloud-resolving models but also for bulk microphysical parameterizations in global models.

\section{Model description}

The hybrid microphysical cloud model was developed to produce accurate estimates of the number concentration of cloud droplets and the effect of $\mathrm{CCN}$ on the microstructure of clouds. This hybrid cloud microphysical model estimates the maximum values of supersaturation and the number concentration of cloud droplets using a parcel model with a Lagrangian framework. This hybrid cloud microphysical model also uses a bin model in the grid point model with semiLagrangian or Eulerian frameworks to estimate condensation, coalescence, sedimentation, and advection of cloud droplets and raindrops. Table 1 shows the two schemes.

\subsection{Cloud microphysical model (Lagrangian framework)}

CCN activation for each grid point is estimated by a parcel model. When the relative humidity at a grid point reaches $100 \%$ for the first time, or when relative humidity at a grid point exceeds $100 \%$ but no cloud water exists on the windward side of the grid point, an air parcel that includes CCN and vapor starts to rise from the windward side of the grid point.

$\mathrm{CCN}$ activation and the initial growth of cloud droplets by condensation are computed in a Lagrangian framework that incorporates the solute effect on CCN. This method precludes numerical diffusion of droplet size distribution. CCN size distributions are approximated using discrete radii classes with prudent choices of initial values. The number of $\mathrm{CCN}$ included in one class should be small compared to the number of activated cloud droplets. In this study, CCN (up to $12 \mu \mathrm{m}$ in radius) are partitioned into 185 separate classes, of which more than 100 classes can be activated and evolve into cloud droplets. It means that an error in cloud droplet number is smaller than $1 \%$.

$\mathrm{CCN}$ with lower critical supersaturation are activated earlier. If all $\mathrm{CCN}$ prepared as input are activated, there is an opportunity that aerosol particles with higher critical supersaturation than input $\mathrm{CCN}$ can be activated. Therefore the minimum input $\mathrm{CCN}$ radius must be smaller than the radius 
Table 1. The two computational schemes for cloud microphysical model.

\begin{tabular}{lll}
\hline & Parcel model & Bin model \\
\hline Framework & Lagrangian & $\begin{array}{l}\text { semi-Lagrangian } \\
x_{i}=x_{1} 2^{(i-1) / k}\end{array}$ \\
Fixed values & $n_{j}$ & Representative mass of droplets \\
& Concentration of CCN & included in each bin. \\
& included in each class. & $(k=2, i=1, \ldots, 71)$ \\
Variable values & $(j=1, \ldots, 185)$ & $n_{i}(t)$ \\
& $x_{j}(t)$ & Concentration of droplets \\
& Mass of droplets forming & included in each bin. \\
Activation & on CCN included in each class. & not considered \\
Condensation & Takeda and Kuba (1982) & Chen and Lamb (1994) \\
Coalescence & not considered & Chen and Lamb (1994) \\
$\Delta t$ & $0.05 \mathrm{~s}$ & $0.5 \mathrm{~s}$ (condensation), <0.5 s (coalescence)
\end{tabular}

of the smallest CCN that can be activated. The simulated results would be invalid if all $\mathrm{CCN}$ were activated.

Based on previous studies (Mordy, 1959; Fitzgerald, 1974; Feingold et al., 1999), we assumed that CCN smaller than $0.1 \mu \mathrm{m}$ in radius, and $\mathrm{CCN}$ larger than $1 \mu \mathrm{m}$ in radius, are initially assumed to be in equilibrium at $99 \%$ and $90 \% \mathrm{RH}$ respectively, at cloud base $(100 \% R H)$. Intermediate CCN are initially assumed to be in equilibrium between 99 and $90 \% R H$ as a function of radius. In spite of selected arbitrarily, the initial sizes of the nuclei are probably not unrealistic (Fitzgerald, 1974). Initial size in this study is smaller than that described in Chen and Liu (2004) (updraft velocity is $1 \mathrm{~m} \mathrm{~s}^{-1}$ in their study). Even if the initial radii are underestimated, droplets approach quickly their appropriate radii. Therefore underestimation of initial radius does not cause any serious errors in cloud droplet number. Considering the possibility of the faster updraft than $1 \mathrm{~m} \mathrm{~s}^{-1}$, the initial radius is set as the aforesaid remark.

In this study, parcel model carries separate CCN size distribution which is modified only by condensation, because parcel model is only used to produce the initial cloud droplet size distribution for bin method and to estimate the inflow of cloud droplets from the windward with no cloud water. $\mathrm{CCN}$ transportation and recycling are not handled here. They can be treated by an appropriate aerosol transportation model in future work.

The time evolution of the representative droplet radius in each class is calculated as detailed in Takeda and Kuba (1982) and Kuba et al. (2003). The time step in this model is $0.05 \mathrm{~s}$. Because droplets approach their equilibrium radius and do not exceed it before they reach their critical radius, short time step of time integration is needed. In case $0.05 \mathrm{~s}$ is not short enough, the growth by condensation of each droplet during each step is limited so that the radius of each droplet does not exceed its equilibrium radius.

When droplets condensed on CCN grow large enough to be distinguished from non-activated nuclei (usually it takes
20 80 s depending on updraft after the humidity reaches $100 \%$ ), the cloud droplets' size distribution calculated by the parcel model is assigned to the grid point as the initial cloud droplet size distribution for the bin model. The mixing ratio of vapor and potential temperature in the parcel are also assigned to the grid point.

When relative humidity at a grid point exceeds $100 \%$ (cloud droplets exist already) but no cloud water exists on the windward side of the grid point, the inflow of cloud droplets from the windward side of the grid point is estimated by using the cloud droplet size distribution in the parcel model. This means the inflow of new activated droplets at cloud base (a kind of a source of droplets).

$\mathrm{CCN}$ activation is only considered at the grid points with cloud water smaller than a critical value $\left(1.5 \mathrm{e}-5 \mathrm{gg}^{-1}\right)$ in this study for simplicity. If updraft velocity is increasing rapidly and cloud droplet concentration is very low, activation may be possible at the grid points with cloud water larger than the critical value. It will be considered in future work.

\subsection{Cloud microphysical model (Semi-Lagrangian frame- work)}

The cloud droplet size distribution at a grid point is formulated using bins of fixed masses. Representative masses for each bin are given by $x_{i}=x_{1} 2^{(i-1) / k}$, where $k$ represents the fineness of classification. The time evolutions of the number and total mass ( $n_{i}$ and $m_{i}$, respectively) of droplets with masses between the two boundaries of the i-th bin, that is, between $b_{i}=x_{i} 2^{-1 / 2 k}$ and $b_{i+1}=x_{i+1} 2^{-1 / 2 k}$, are computed.

The equations governing the growth rate of droplets by condensation are those in Takeda and Kuba (1982). The equation governing the coalescence-forced rate of change of the cloud droplet spectrum over time is stochastic. Collision efficiency is computed from Table 1 in Hall (1980). Fall velocity is estimated by using equations described in FORTRAN code distributed by Bott (1998). Both rain drops and cloud droplets are all handled in one bin scheme. 


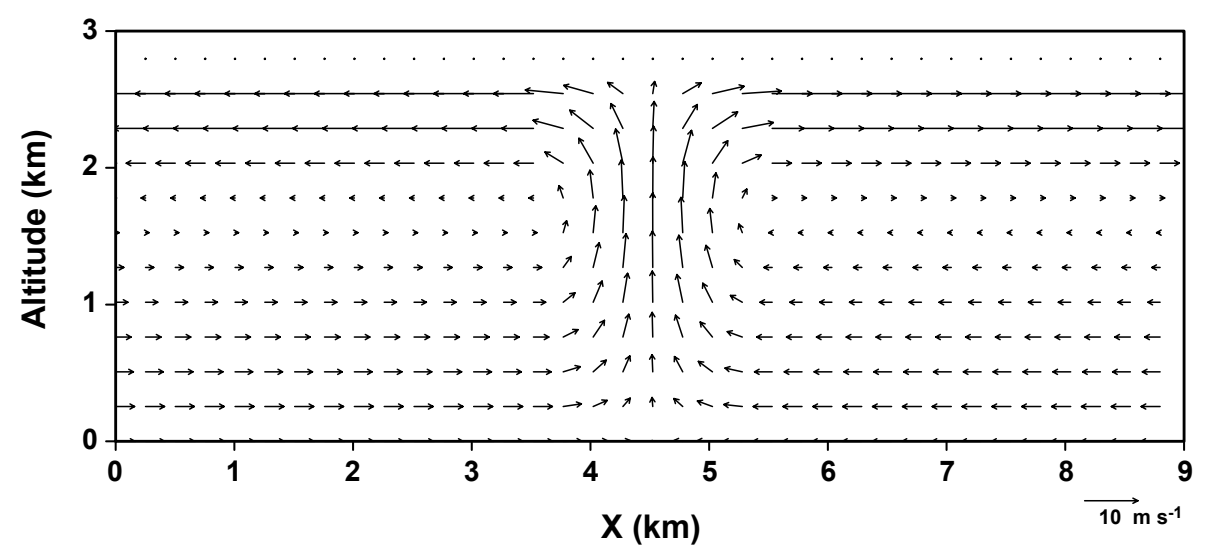

Fig. 1. Wind field at $25 \mathrm{~min}$, corresponding to the peak updraft.

Table 2. The ratio of the number of $\mathrm{CCN}$ in each case to that in case A.

\begin{tabular}{cccc}
\hline Case & $\begin{array}{c}\text { small particle CCN } \\
(0.1 \mu \mathrm{m}<\text { radius })\end{array}$ & $\begin{array}{c}\text { large particle CCN } \\
(0.1<\text { radius }<1 \mu \mathrm{m})\end{array}$ & $\begin{array}{c}\text { giant particle CCN } \\
(1 \mu \mathrm{m}<\text { radius })\end{array}$ \\
\hline $\mathrm{A}$ & 1 & 1 & 1 \\
$\mathrm{~B}$ & 5 & 1 & 1 \\
$\mathrm{C}$ & 10 & 1 & 1 \\
$\mathrm{D}$ & 1 & 5 & 1 \\
$\mathrm{E}$ & 10 & 5 & 1 \\
$\mathrm{~F}$ & 1 & 1 & 5 \\
$\mathrm{G}$ & 1 & 1 & 0 \\
$\mathrm{H}$ & 10 & 1 & 5 \\
$\mathrm{I}$ & 10 & 1 & 0 \\
\hline
\end{tabular}

Time changes due to growth by condensation and coalescence are calculated in the semi-Lagrangian framework by using the two-moment bin method developed by Chen and Lamb (1994) to minimize numerical diffusion of cloud droplet size distribution. Additionally fine resolution $(k=2$ in this study) is used. There are 71 bins for radii between $1 \mu \mathrm{m}$ and $3.25 \mathrm{~mm}$.

The time steps for growth by condensation and coalescence are $0.5 \mathrm{~s}$, but the time step for coalescence can be shortened to prevent multiple collisions in one time step (the shortest time step for coalescence is $0.005 \mathrm{~s}$ ). Sedimentation and advection of droplets are estimated in the Eulerian framework among grid points.

The solute effect on cloud droplet growth by condensation is not considered here. This simplification introduces little error because almost all cloud droplets are sufficiently dilute at this stage, with the exception of those unusual droplets that form on rare, large $\mathrm{CCN}$. However, these large drops grow mostly by coalescence and the condensational growth rate $(d r / d t)_{\text {cond }}$ is much smaller than $r$. Underestimating the growth rate due to condensation alone does not significantly affect estimates of their overall growth rate. Details on such underestimates of growth rate are in the appendix of Kuba et al. (2003).

\section{Numerical experiments}

The dynamical framework of this study was designed to test the warm rain microphysical model Case 1 of the fifth WMO Cloud Modeling Workshop (Szumowski et al., 1998). The dynamical cloud model predicts an evolving flow for $50 \mathrm{~min}$ and performs a two-dimensional advection of the temperature and water variables (domain: $9 \mathrm{~km} \times 3 \mathrm{~km}, d x$ and $d z$ : $50 \mathrm{~m}, d t: 3 \mathrm{~s}$ ). The flow pattern shows low level convergence, upper level divergence, and a narrow updraft located in the center of the domain. The magnitude, vertical structure, width and tilt of the flow through the central updraft are all prescribed using simple analytical functions. The updraft is held constant at $1 \mathrm{~m} \mathrm{~s}^{-1}$ for the first $15 \mathrm{~min}$ of the simulation. The updraft intensifies to a peak value of $8 \mathrm{~m} \mathrm{~s}^{-1}$ at $25 \mathrm{~min}$ and subsequently decays to a value of $2 \mathrm{~m} \mathrm{~s}^{-1}$ at 40 min. During the 10 -min rain out time at the end of the 50-min simulation, the updraft is held constant at $2 \mathrm{~m} \mathrm{~s}^{-1}$ (Szumowski et al., 1998). This dynamical framework predicts updraft velocity, water vapor, and potential temperature explicitly. The bulk microphysical scheme imbedded in original Szumowski's model was replaced with our hybrid microphysical model in this study. The advection scheme is a modified version of that by Smolarkiewicz (1984). Figure 1 shows the wind field at $25 \mathrm{~min}$, the time that corresponds to the peak updraft.

This simple model cannot estimate the effect of rainfallinduced drag on the dynamics. The effect of the change in drag caused by $\mathrm{CCN}$ differences will be studied in subsequent work. However, the model can estimate the effects of $\mathrm{CCN}$ on cloud microstructure and rainwater generation.

Updraft velocity and water vapor determine the liquid water content, aerosol properties and updraft velocity determine the number of cloud droplets, liquid water content and cloud droplet number determine the cloud droplet size distribution. Therefore primary factors determining the cloud properties are water vapor and updraft velocity. In addition, aerosol properties determine cloud microstructure. In this study the 


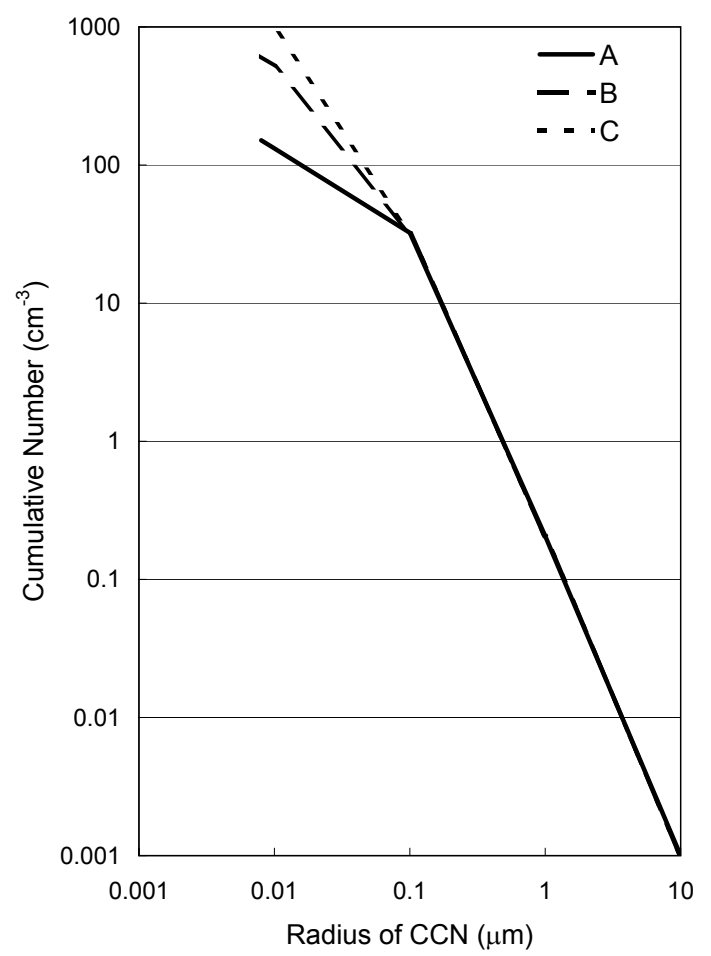

Fig. 2. Three CCN size distributions (A, B, and C) used in this study. The ratios of the number of small-particle $\mathrm{CCN}$ (radius $<0.1 \mu \mathrm{m}$ ) in $\mathrm{B}$ and $\mathrm{C}$ to $\mathrm{A}$ are 5 and 10 , respectively.

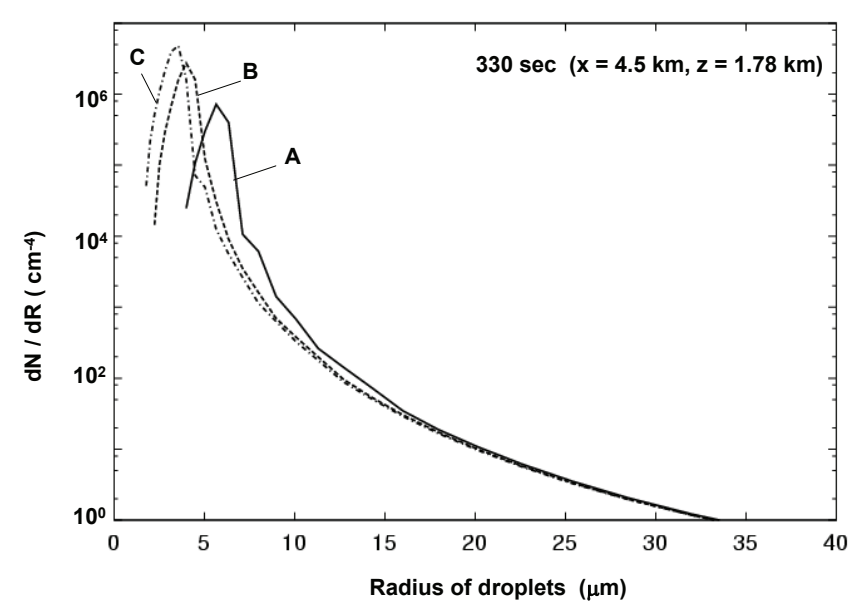

Fig. 3. Cloud droplet size distributions at the cloud base, at the center of the cloud, at $5.5 \mathrm{~min}$ for cases $\mathrm{A}, \mathrm{B}$, and $\mathrm{C}$. The concentrations of cloud droplets in cases A, B, and C are 103,325 , and $550 \mathrm{~cm}^{-3}$, respectively.

effect of aerosol particles those can be $\mathrm{CCN}$ on cloud microstructure is investigated in detail.
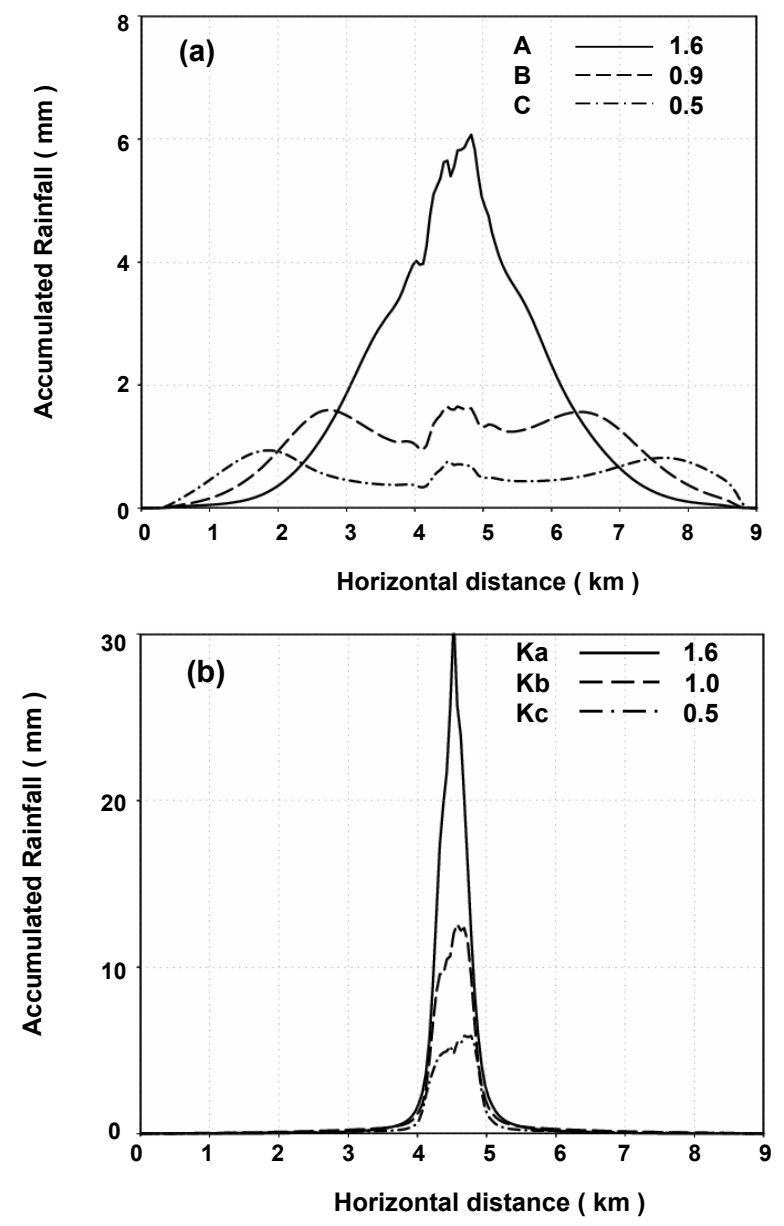

Fig. 4. Accumulated rainfall at $50 \mathrm{~min}$. (a) Cases $\mathrm{A}, \mathrm{B}$, and $\mathrm{C}$. Values averaged in the domain for cases $\mathrm{A}, \mathrm{B}$, and $\mathrm{C}$ are $1.6 \mathrm{~mm}$, $0.9 \mathrm{~mm}$, and $0.5 \mathrm{~mm}$ respectively. (b) Three cases using Kessler's parameterization. Values averaged in the domain for cases $\mathrm{Ka}, \mathrm{Kb}$, and $\mathrm{Kc}$ are $1.6 \mathrm{~mm}, 1.0 \mathrm{~mm}$, and $0.5 \mathrm{~mm}$, respectively.

\subsection{Effect of small-particle CCN}

We used the three $\mathrm{CCN}$ size distributions (A, B, and C) (Fig. 2) to study the effect of the number of small-particle CCN. A, B, and C are typical size distributions for clean maritime, lightly polluted maritime, and heavily polluted maritime CCN respectively. The difference between the three cases is the number of small CCN (radius $<0.1 \mu \mathrm{m}$ ). Their ratios are 1,5 , and 10 , respectively. Table 2 lists the ratio of the number of $\mathrm{CCN}$ in each case to that in case A for the three size regimes (small, large, and giant particles). For simplicity, all $\mathrm{CCN}$ are assumed to be $\mathrm{NaCl}$ and all grid points have same CCN size distribution in this study.

Figure 3 shows cloud droplet size distributions at the cloud base, at the center of the cloud, at $5.5 \mathrm{~min}$ for the three cases. The concentrations of cloud droplets for cases A, B, and $\mathrm{C}$ are 103,325 , and $550 \mathrm{~cm}^{-3}$, respectively. Larger numbers of small-particle CCN lead to a smaller mode radius for 

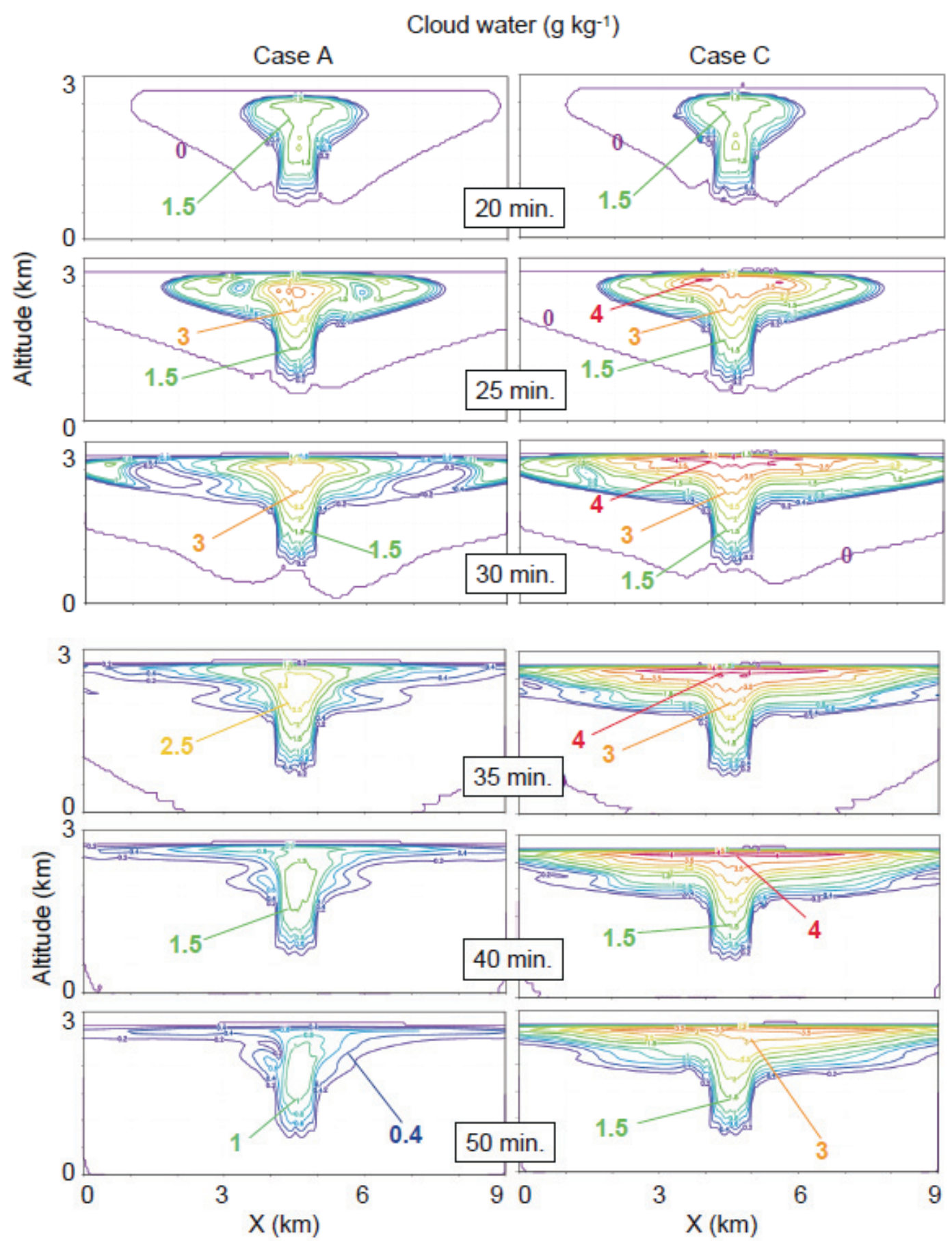

Fig. 5. Cloud water mixing ratio in cases $\mathrm{A}$ and $\mathrm{C}$ at 20, 25, 30, 35, 40, and $50 \mathrm{~min}$.

cloud droplets. Figure 4 a shows the accumulated rainfall at $50 \mathrm{~min}$ for three cases. The figure also lists values averaged in the domain. Smaller rainfall amounts result from the case with larger numbers of $\mathrm{CCN}$, in agreement with many studies (Twomey, 1974; Albrecht et al., 1995; Saleeby and Cotton, 2004). It is also shown in Fig. 4a that the more CCN lead to the more widespread rainfall area. This study shows that rainfall area is also affected by the number of $\mathrm{CCN}$ because increased numbers of small CCN significantly reduce not only the rainwater production rate but also the fall velocity of the raindrops as a result of their smaller size. Small rain droplets can not fall against the strong updraft at the center of this cloud, they need longer time to become large enough to fall even in no updraft area (outer area in this study). To 

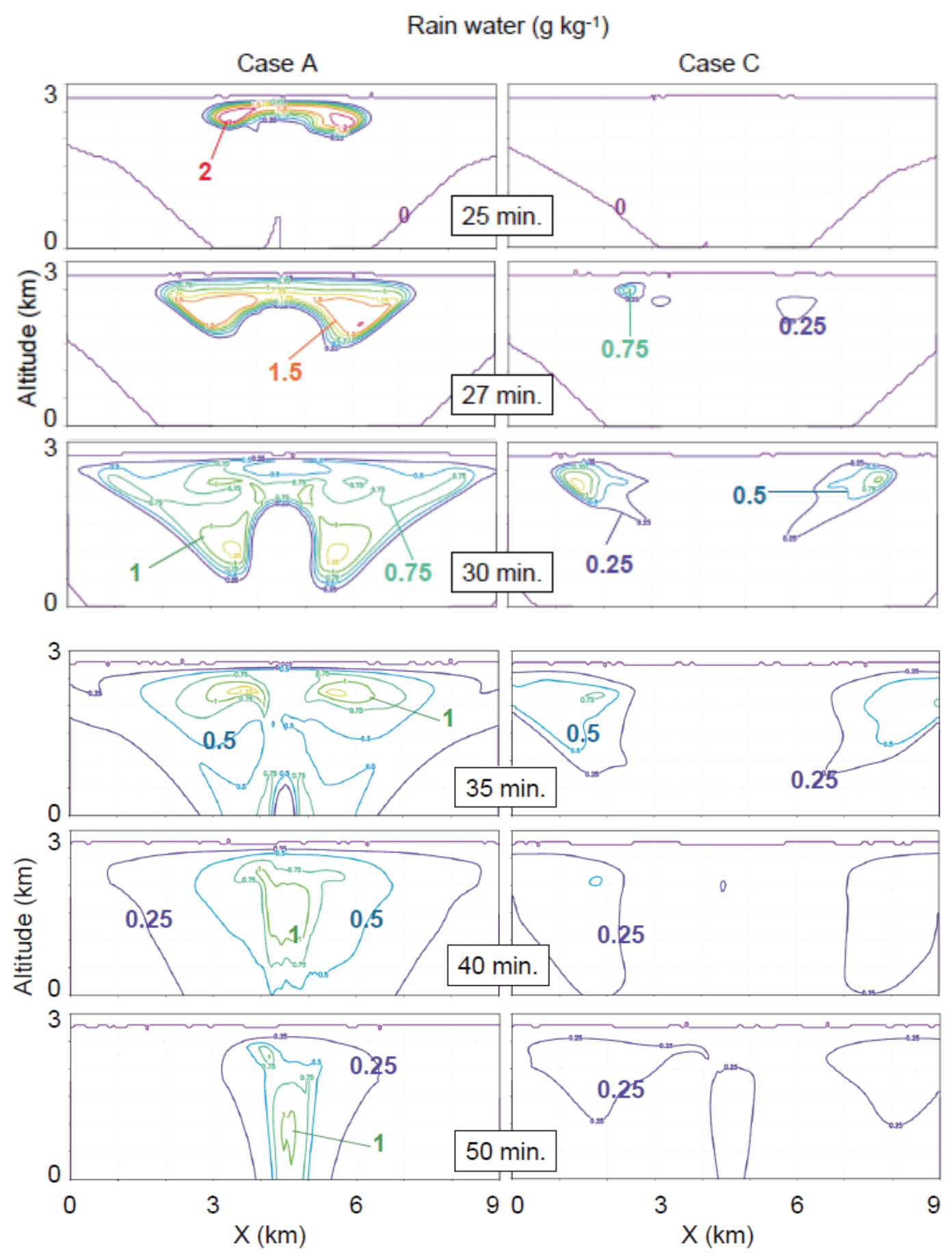

Fig. 6. Rain water mixing ratio in cases $\mathrm{A}$ and $\mathrm{C}$ at 25, 27, 30, 35, 40, and $50 \mathrm{~min}$.

clear the difference in rain water production, cloud water and rain water distribution in cases $\mathrm{A}$ and $\mathrm{C}$ are shown in Figs. 5 and 6.

This hybrid cloud-microphysical model can be used to validate the results of a bulk parameterization as follows. Kessler's parameterization was installed in the same kinematic framework for comparison. The parameterization is expressed as follows (Cotton and Anthes, 1989):

$R=\alpha\left(Q_{c}-Q_{c 0}\right) H\left(Q_{c}-Q_{c 0}\right)+\beta Q_{c} Q_{r}^{0.875}$

where $R$ is the production rate of rainwater, $Q_{c}$ and $Q_{r}$ are the mixing ratios of cloud water and rain water, and $\alpha, \beta$ and $Q_{c 0}$ are constants. $H\left(Q_{c}-Q_{c 0}\right)$ is the Heaviside function that is introduced to represent the threshold process. The 

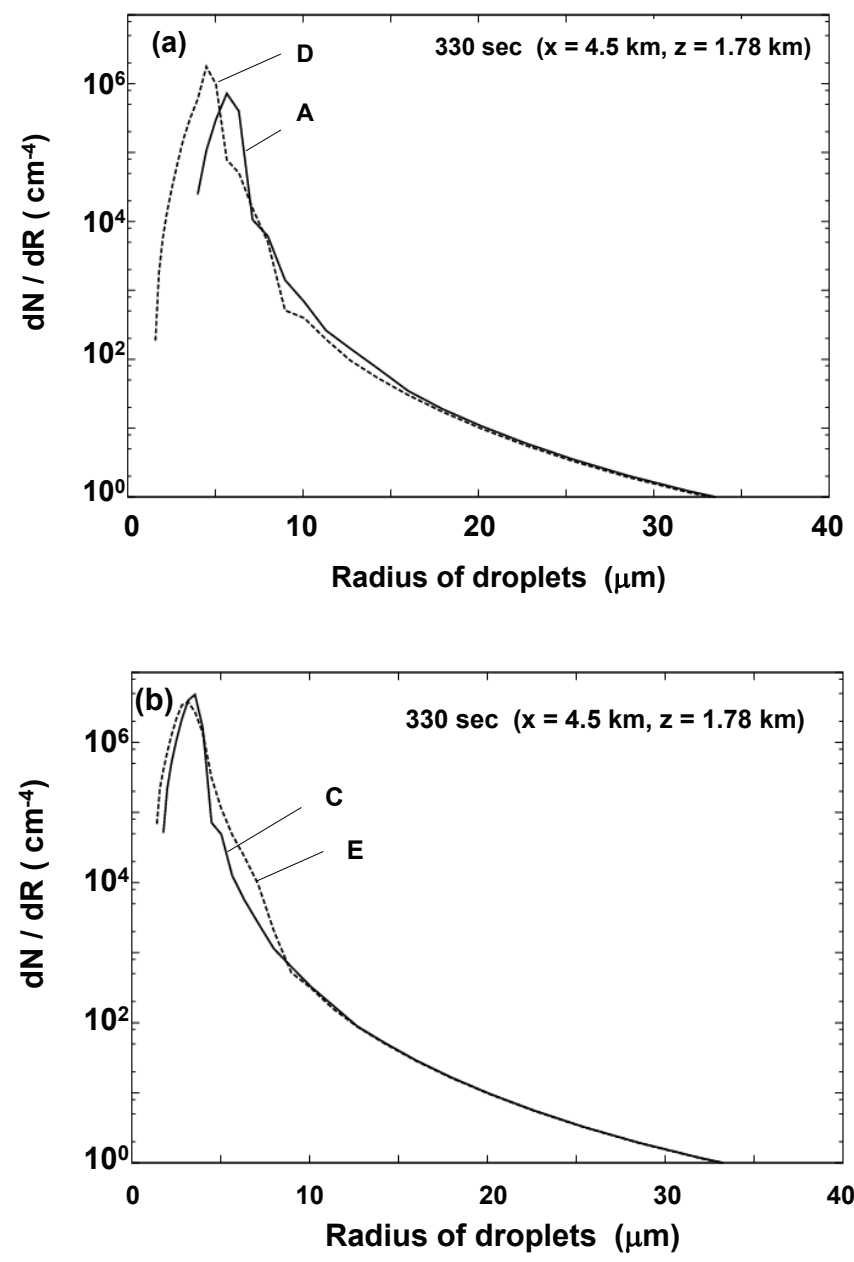

Fig. 7. Cloud droplet size distributions at the cloud base, at the center of the cloud, at $5.5 \mathrm{~min}$. (a) Cases A and D (in case D, largeparticle $\mathrm{CCN}$ are added to case A). The concentrations of cloud droplets in cases A and D are 103 and $209 \mathrm{~cm}^{-3}$, respectively. (b) Cases $\mathrm{C}$ and $\mathrm{E}$ (in case $\mathrm{E}$, large-particle $\mathrm{CCN}$ are added to case $\mathrm{C}$ ). The concentrations of cloud droplets in cases $\mathrm{C}$ and $\mathrm{E}$ are 550 and $583 \mathrm{~cm}^{-3}$, respectively.

following typical combination of values is used here, following the code distributed by Szumowski et al. (1998):

$\left(\alpha, \beta, Q_{c 0}\right)=(0.001,2.2,0.0005)$

The terminal fall velocity $V_{t}\left(\mathrm{~cm} \mathrm{~s}^{-1}\right)$ of rain water is assumed to be

$V_{t}=V_{0}(1000 \rho)^{-0.5}\left(\rho Q_{r}\right)^{\gamma}$

where $\rho$ is air density $\left(\mathrm{g} \mathrm{cm}^{-3}\right)$. As in the code distributed by Szumowski et al. (1998), the following values are used:

$\left(V_{0}, \gamma\right)=(36.34,0.136)$

Mean rainfall amount in the domain at 50 minutes calculated from simulations using these values is $1.37 \mathrm{~mm}$. A situation
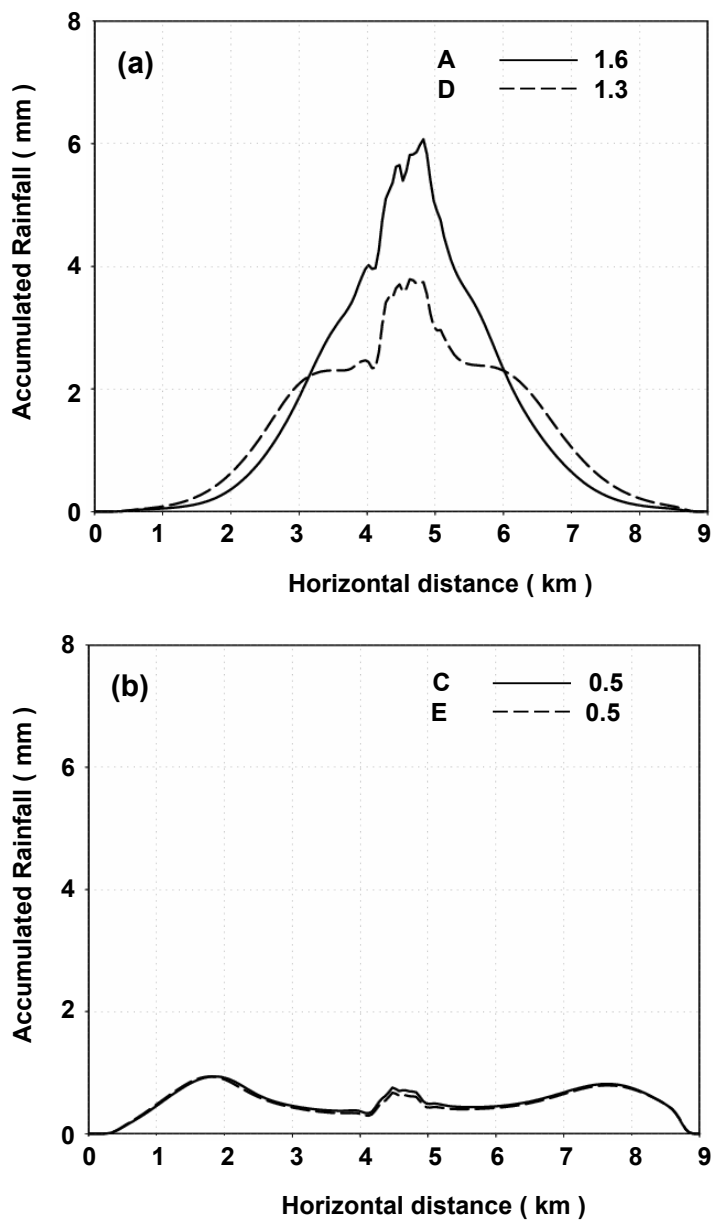

Fig. 8. Accumulated rainfall at $50 \mathrm{~min}$. (a) Cases A and D. Values averaged in the domain for cases $A$ and $D$ are $1.6 \mathrm{~mm}$ and $1.3 \mathrm{~mm}$, respectively. (b) Cases $\mathrm{C}$ and $\mathrm{E}$. Values averaged in the domain for cases $\mathrm{C}$ and $\mathrm{E}$ are $0.5 \mathrm{~mm}$ and $0.5 \mathrm{~mm}$, respectively.

similar to cases A, B, and C was simulated with different values of $\left(\alpha, \beta, Q_{c 0}\right)$ as follows:

$\left(\alpha, \beta, Q_{c 0}\right)=(0.003,2.2,0.0005) \quad$ for case $\mathrm{Ka}$

$\left(\alpha, \beta, Q_{c 0}\right)=(0.001,1.1,0.0005) \quad$ for case $\mathrm{Kb}$

$\left(\alpha, \beta, Q_{c 0}\right)=(0.0005,1.1,0.001) \quad$ for case Kc.

These combinations of $\left(\alpha, \beta, Q_{c 0}\right)$ are determined based on trial and error simulations considering $\mathrm{CCN}$ properties.

Figure $4 \mathrm{~b}$ shows the accumulated 50-min rainfall for these cases. The combination of coefficients produced a mean rainfall amount in the domain of $1.6 \mathrm{~mm}, 1.0 \mathrm{~mm}$, or $0.5 \mathrm{~mm}$, respectively. Adjusting the coefficients $\left(\alpha, \beta, Q_{c 0}\right)$ controls the averaged accumulated rainfall. However the horizontal distributions of rainfall amounts in Fig. $4 \mathrm{~b}$ are very different from those in Fig. 4a, because the bulk model cannot accurately express differences in fall velocity for raindrops with a wide range of radii $(40 \mu \mathrm{m} \sim 2 \mathrm{~mm}$ ). On the other hand, the 

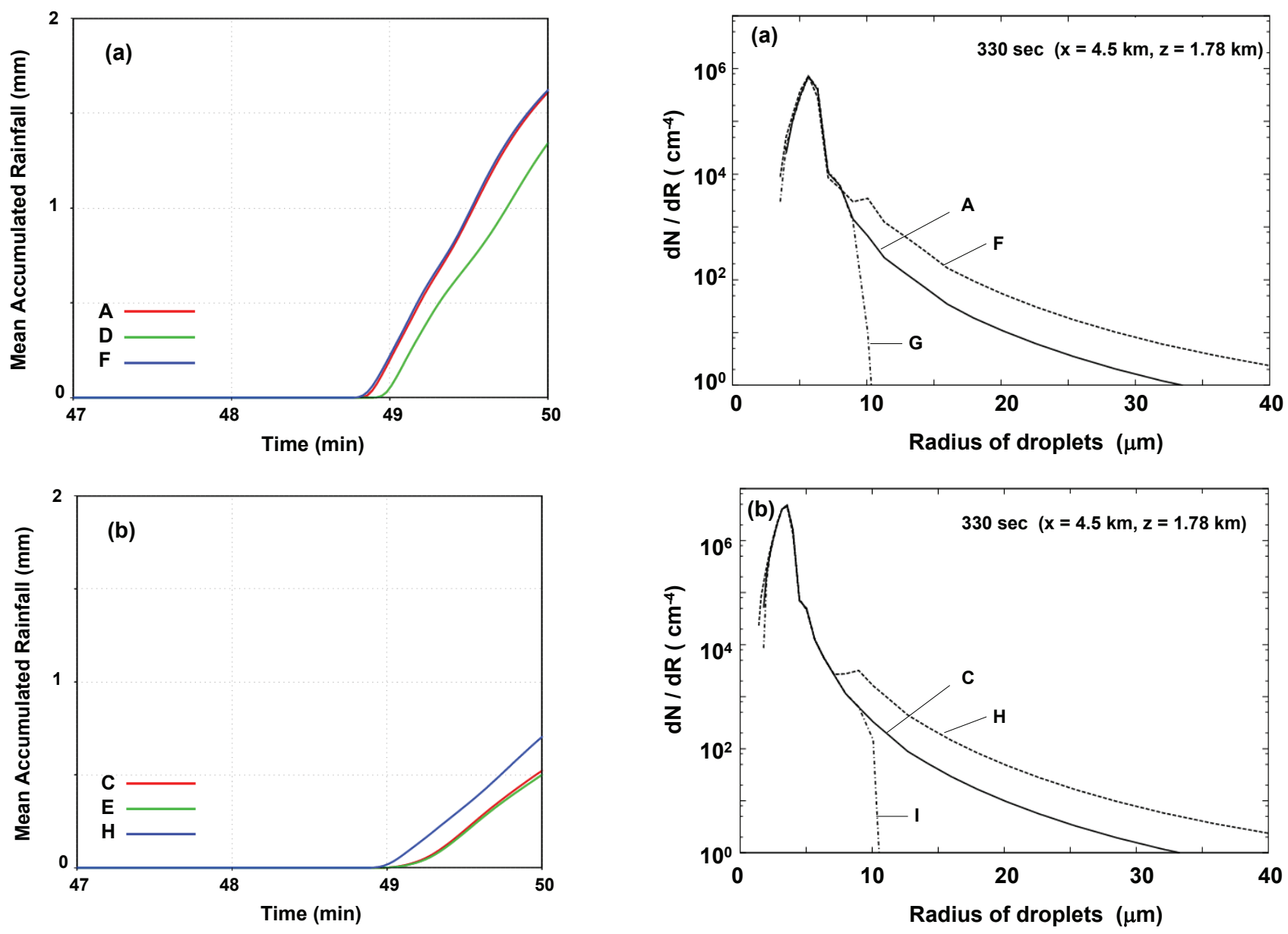

Fig. 9. Time changes of accumulated rainfall averaged in the domain for cases A, D, F, C, E, and $\mathrm{H}$.

bin model can estimate the fall velocity of raindrops for each bin.

\subsection{Effect of large-particle CCN}

Cases D and E, described next, investigate the role of the large-particle CCN $(0.1 \mu \mathrm{m}<$ radius $<1 \mu \mathrm{m})$ in warm cloud. Case D adds large-particle $\mathrm{CCN}$ to case A (clean maritime case). Case E adds large-particle $\mathrm{CCN}$ to case $\mathrm{C}$ (smallparticle rich case). In both cases large particle $\mathrm{CCN}$ are added mainly in the size range between 0.1 and $0.8 \mu \mathrm{m}$, moderately in the size ranges between 0.08 and $0.1 \mu \mathrm{m}$ and between 0.8 and $1.0 \mu \mathrm{m}$. Figure $7 \mathrm{a}$ shows the cloud droplet size distributions at the cloud base, at the center of the cloud, at $5.5 \mathrm{~min}$ for cases $\mathrm{A}$ and D. The cloud droplet concentrations for cases A and D are 103 and $209 \mathrm{~cm}^{-3}$, respectively. Similarly, Fig. 7b shows cloud droplet size distributions for cases $\mathrm{C}$ and $\mathrm{E}$; the cloud droplet concentrations are 550 and $583 \mathrm{~cm}^{-3}$, respectively. Figure 7 shows that adding largeparticle $\mathrm{CCN}$ reduces the mode radius of cloud droplets and that this effect is larger for cases with fewer CCN. If there are

Fig. 10. Cloud droplet size distributions at the cloud base, at the center of the cloud, at $5.5 \mathrm{~min}$. (a) Cases A, F, and G (Case F: giant $\mathrm{CCN}$ are added to case A; Case G: giant $\mathrm{CCN}$ are removed from case A). The concentrations of cloud droplets for cases A, F, and $\mathrm{G}$ are 103,102 , and $103 \mathrm{~cm}^{-3}$, respectively. (b) Cases $\mathrm{C}, \mathrm{H}$, and I (Case $\mathrm{H}$ : giant $\mathrm{CCN}$ are added to case $\mathrm{C}$; Case I: giant $\mathrm{CCN}$ are removed from case $\mathrm{C}$ ). The concentrations of cloud droplets for cases $\mathrm{C}, \mathrm{H}$, and $\mathrm{I}$ are 550,541 , and $550 \mathrm{~cm}^{-3}$, respectively.

many $\mathrm{CCN}$, adding large-particle $\mathrm{CCN}$ increases the number of large cloud droplets.

Figure 8a shows accumulated rainfall at $50 \mathrm{~min}$ for cases A and D. Adding large-particle CCN decreases the amount of rainfall for cases with small numbers of small-particle CCN. Figure $8 \mathrm{~b}$ shows accumulated rainfall at $50 \mathrm{~min}$ for cases $\mathrm{C}$ and E. Adding large-particle $\mathrm{CCN}$ does not affect rainfall amounts when there are large numbers of small-particle CCN. Rainwater is produced mainly from water condensed on small-particle $\mathrm{CCN}$ for the cases with small numbers of $\mathrm{CCN}$ (cases A and D). In this case, adding large-particle $\mathrm{CCN}$ suppresses the growth rate of droplets condensed on small-particle $\mathrm{CCN}$. Water condensed on large $\mathrm{CCN}$ does not produce a lot of rain in any case. Time changes of accumulated rainfall averaged in the domain in cases A, D, C, and 

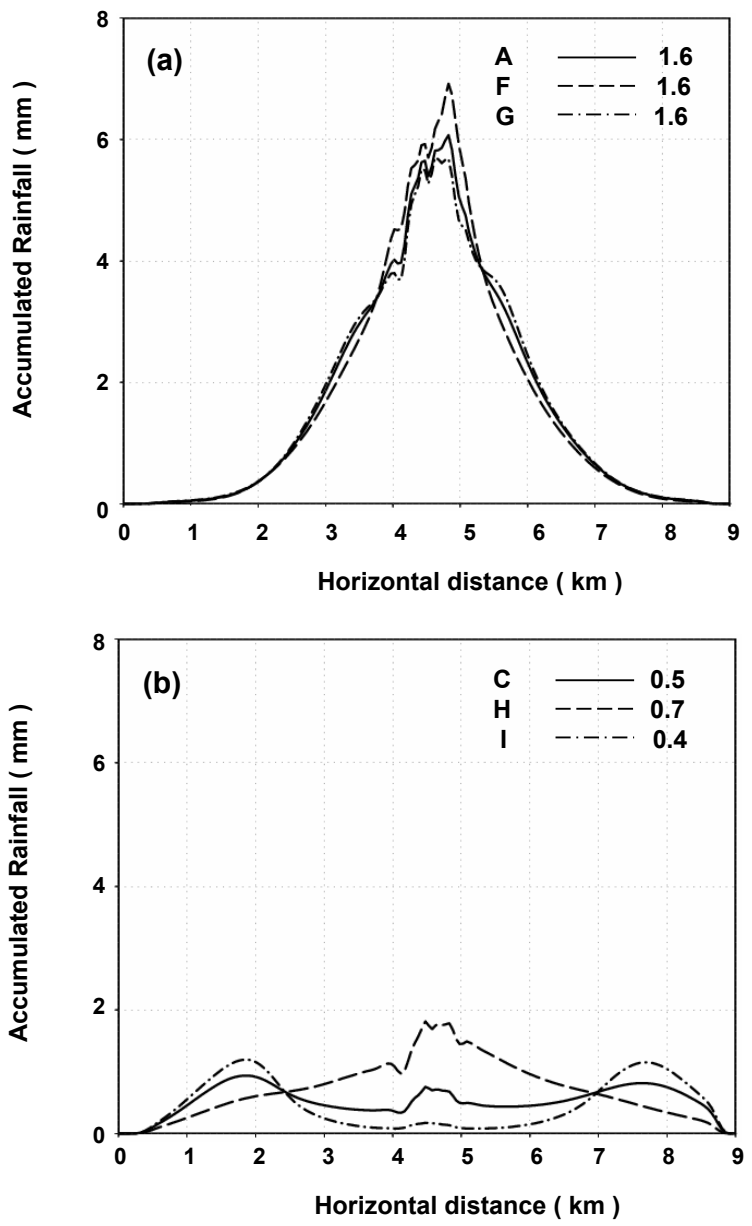

Fig. 11. Accumulated rainfall at $50 \mathrm{~min}$. (a) Cases A, F, and G. Values averaged in the domain for cases $\mathrm{A}, \mathrm{F}$, and $\mathrm{G}$ are $1.6 \mathrm{~mm}$, $1.6 \mathrm{~mm}$, and $1.6 \mathrm{~mm}$, respectively. (b) Cases C, H, and I. Values averaged in the domain for cases $\mathrm{C}, \mathrm{H}$, and $\mathrm{I}$ are $0.5 \mathrm{~mm}, 0.7 \mathrm{~mm}$, and $0.4 \mathrm{~mm}$, respectively.

E are shown in Fig. 9. It is shown that adding large particle $\mathrm{CCN}$ does not result in faster precipitation in both clean maritime case and heavily polluted maritime case.

\subsection{Effect of giant-particle CCN}

Cases F-I, described below, help define the role of giantparticle CCN (radius $>1 \mu \mathrm{m}$ ) in warm cloud. Case $\mathrm{F}$ adds giant $\mathrm{CCN}$ to case A (clean maritime case), and case $\mathrm{G}$ removes giant $\mathrm{CCN}$ from case $\mathrm{A}$. Case $\mathrm{H}$ adds giant $\mathrm{CCN}$ to case $\mathrm{C}$ (small-particle rich case) and case I (continental case) removes giant $\mathrm{CCN}$ from case $\mathrm{C}$.

Figures 10a and $\mathrm{b}$ show the cloud droplet size distribution at the cloud base, at the center of the cloud, at $5.5 \mathrm{~min}$ for cases $\mathrm{A}, \mathrm{F}, \mathrm{G}, \mathrm{C}, \mathrm{H}$, and I; cloud droplet concentrations are $103,102,103 \mathrm{~cm}^{-3}, 550,541$, and $550 \mathrm{~cm}^{-3}$, respectively. The addition of giant $\mathrm{CCN}$ does not affect the mode radius of cloud droplets, but it does affect the num- ber of large cloud droplets. Figures $11 \mathrm{a}$ and $\mathrm{b}$ show accumulated rainfall at $50 \mathrm{~min}$ for cases $\mathrm{A}, \mathrm{F}, \mathrm{G}, \mathrm{C}, \mathrm{H}$, and $\mathrm{I}$. Figure 11a shows that the addition of giant-particle CCN increases the rainfall at the center of cloud. It is because that drops condensed on giant-particle $\mathrm{CCN}$ become large enough to fall against the strong updraft at the center of cloud. However many droplets condensed on CCN smaller than $1.0 \mu \mathrm{m}$, also grow enough to start coalescence growth, and become rain drops. Therefore addition of giant $\mathrm{CCN}$ does not dramatically affect rainfall for cases with small numbers of CCN (Fig. 11a). For cases with small numbers of small-particle $\mathrm{CCN}$, rainwater mainly originates from water condensed on small-particle CCN. In contrast, if there are many small-particle $\mathrm{CCN}$, the more giant-particle $\mathrm{CCN}$ leads to the higher amounts of rainfall (Fig. 11b). When there are many small-particle $\mathrm{CCN}$, droplets condensed on small-particle $\mathrm{CCN}$ can not grow enough to start coalescence growth, and then rainwater originates mostly from water condensed on giant-particle $\mathrm{CCN}$ and droplets caught by droplet condensed on giant-particle CCN. These results agree with the results in Kuba and Takeda (1983), Cooper et al. (1997), Feingold et al. (1999), and Saleeby and Cotton (2004), in which they showed that the effect of giant-particle $\mathrm{CCN}$ on rainfall efficiency of clouds is most remarkable in cases with numerous small-particle CCN. Additionally this study shows clearer differences in rainfall amounts and in the area of precipitation that arise from differences in the $\mathrm{CCN}$ spectrum.

Time changes of accumulated rainfall averaged in the domain for cases of A, F, C, and $\mathrm{H}$ are shown in Fig. 9 to see the beginning of precipitation. It is found that the formation of rain is accelerated only when giant particle $\mathrm{CCN}$ are added to the case with a large number of small $\mathrm{CCN}$.

\section{Parameterizations}

4.1 Parameterization to predict cloud droplet number and its application in AGCM

Section 3 showed that the most influential CCN factor is the number of small-particle CCN. A parameterization is developed to relate cloud droplet number $\left(N_{d} \mathrm{~cm}^{-3}\right)$ to the updraft velocity at the cloud base $\left(V_{\text {base }} \mathrm{m} \mathrm{s}^{-1}\right)$ and the cumulative number of CCN that can be activated at $S \%$ supersaturation $\left(N_{c}(S) \mathrm{cm}^{-3}\right)$ (Kuba et al., 2003; Kuba and Iwabuchi, 2003). In this study, those factors are extended for a wider range of updraft velocities, as in Kuba and Iwabuchi (2003). The numerous numerical experiments using parcel model and many kinds of CCN spectrum derived the most correlative factor $N_{c}(S)$ with cloud droplet number. $S$ in $N_{c}(S)$ is not necessarily the maximum value of $S\left(S_{\max }\right)$ realized in the simulation. In many studies, Twomey's (1959) relationship is used to estimate the number of activated CCN, i.e. $N_{\mathrm{act}}=C S_{\mathrm{max}}^{k}$. This method tends to overestimate the number of activated $\mathrm{CCN}$, or the number of cloud droplets. In our previous studies, it 
is shown that even after growing beyond their critical radii, some CCN revert to being inactivated after supersaturation has reached its maximum value. It is because that supersaturation does not keep its maximum value and decreases rapidly. Chuang et al. (1997) and Yun and Hudson (2002) also noted this overestimation, which is caused by assuming that the cloud droplet concentration is equal to the concentration of CCN for which critical supersaturation is lower than the maximum supersaturation in the cloud. Our parameterization takes this effect into account. In this parameterization, $N_{c}(S)$ includes all aerosol particles. Therefore competition of water vapor among aerosol species are taken into account under the assumption that aerosol particles with the same critical supersaturation behave in the same way except some aerosol particles made of special substance with unusual Koehler curve.

Figure 12 shows relationship between the number of cloud droplets and the number of CCN that can be activated at fixed supersaturation $S \%$. The results of the numerical simulations with many kinds of $\mathrm{CCN}$ size distributions using the cloud microphysical parcel model are shown by marks. Based on these fitting curves approximations are developed as follows;

$$
\begin{array}{cl}
N_{d}=A N_{c}(S) /\left(N_{c}(S)+B\right) & \\
\text { For } V_{\text {base }} \leq 0.24 \mathrm{~m} \mathrm{~s}^{-1}: & S=0.2 \% \\
& A=4710 V_{\text {base }}^{1.19} \\
& B=1090 V_{\text {base }}+33.2 \\
\text { For } 0.24 \leq V_{\text {base }} \leq 0.5 \mathrm{~m} \mathrm{~s}^{-1}: & S=0.4 \% \\
& A=11700 V_{\text {base }}-1690 \\
& B=10600 V_{\text {base }}-1480 \\
\text { For } 0.5 \leq V_{\text {base }} \leq 1.0 \mathrm{~m} \mathrm{~s}^{-1}: & S=0.5 \% \\
& A=4300 V_{\text {base }}^{1.05} \\
& B=2760 V_{\text {base }}^{0.755} \\
\text { For } 1.0 \leq V_{\text {base }} \leq 3.0 \mathrm{~m} \mathrm{~s}^{-1}: & S=1.0 \% \\
& A=7730-15800 \exp \left(-1.08 V_{\text {base }}\right) \\
& B=6030-24100 \exp \left(-1.87 V_{\text {base }}\right) \\
\text { For } 3.0 \leq V_{\text {base }} \leq 10.0 \mathrm{~m} \mathrm{~s}^{-1}: & S=2.0 \% \\
& A=1140 V_{\text {base }}-741 \\
& B=909 V_{\text {base }}-56.2
\end{array}
$$

In case of the larger updraft, we need to count CCN number under the higher supersaturation to get the good correlation between CCN number and droplet number. Critical supersaturations of $0.2 \%, 0.4 \%, 0.5 \%, 1.0 \%$, and $2.0 \%$ correspond to radii of $0.036 \mu \mathrm{m}(0.048 \mu \mathrm{m})$, $0.023 \mu \mathrm{m} \quad(0.031 \mu \mathrm{m}), \quad 0.019 \mu \mathrm{m} \quad(0.027 \mu \mathrm{m}), \quad 0.012 \mu \mathrm{m}$ $(0.017 \mu \mathrm{m})$ and $0.0077 \mu \mathrm{m}(0.011 \mu \mathrm{m})$ for dry nuclei of $\mathrm{NaCl}\left(\left(\mathrm{NH}_{4}\right)_{2} \mathrm{SO}_{4}\right)$, for example. $N_{c}(S)$ for $S=0.2 \%, 0.4 \%$, $0.5 \%, 1.0 \%$, or $2.0 \%$ reflects the number of small $\mathrm{CCN}$ and large $\mathrm{CCN}$. The input information of $\mathrm{CCN}$ for these parameterizations is only several values of $\mathrm{CCN}$ spectrum (they are given by CCN counter for example). It is more convenient than conventional parameterizations those need values concerned with $\mathrm{CCN}$ spectrum, $C$ and $k$ in the equation of $N=C S^{k}$ (as in Twomey, 1959) or, breadth, total number and median radius, for example. This parameterization is valid for soluble constitutes of aerosol particles which have usual Koehler curves.

Typically, global models do not include cloud microphysical models; thus parameterizations will be useful in global models to approximate the effects of aerosol particles. This parameterizations was incorporated into the global model CCSR/NIES/FRCGC-AGCM, which also includes the aerosol transportation model SPRINTARS (Takemura et al., 2000, 2002), to test application of the parameterization. CCSR/NIES/FRCGC-AGCM is an atmospheric general circulation model that has been developed based on CCSR/NIES-AGCM (Numaguti, 1993; Numaguti et al., 1995). Particle radii that correspond to the critical supersaturations $0.2 \%, 0.4 \%, 0.5 \%, 1.0 \%$, and $2.0 \%$, and an assumed size distribution of CCN for each constituent are used to estimate the number of CCN $N_{c}(S)$, because SPRINTARS output is the global distribution of the masses of sea salt particles, sulfate particles, organic carbon particles, black carbon particles, and dust particles. The assumed size distribution is log-normal. Determination of parameters of the log-normal distribution for sea salt particles, sulfate particles, and organic carbon particles are mentioned in Takemura et al. (2000, 2005).

To calculate the particle radius that corresponds to each critical supersaturation, sea salt particles are assumed to be $\mathrm{NaCl}$ and sulfate particles are assumed to be $\left(\mathrm{NH}_{4}\right)_{2} \mathrm{SO}_{4}$. Many different chemical constituents comprise organic carbon particles. It is difficult to treat each chemical constituent separately, so an approximation is needed for the average nature of organic carbon particles in the real atmosphere. The first step is to adopt the approximation derived by Ghan et al. (2001): the material density and hygroscopicity of organic carbon particles are approximately 1 and 0.14 , respectively (see their Table 1). These values allow a calculation of the dry radius for each supersaturation. Critical supersaturations of $0.2 \%, 0.4 \%, 0.5 \%, 1.0 \%$, and $2.0 \%$ correspond to radii of $0.074 \mu \mathrm{m}, 0.047 \mu \mathrm{m}, 0.040 \mu \mathrm{m}, 0.025 \mu \mathrm{m}$, and $0.016 \mu \mathrm{m}$ for a dry nucleus of organic carbon particles. Black carbon and dust particles are assumed insoluble; they become CCN only when coated by water-soluble constituents. Black carbon and dust particles can therefore be excluded from the $\mathrm{CCN}$ if sea salt, sulfate, and organic carbon aerosol particles are estimated sufficiently without regard to whether they are mixed with insoluble matter.

Because CCSR/NIES/FRCGC-AGCM does not resolve the cloud updraft, turbulent kinetic energy is used to estimate updraft velocity as in Lohmann et al. (1999). Figure 13a shows the annual mean value (for 2000) of effective cloud droplet radii at cloud tops warmer than $273 \mathrm{~K}$. These annual mean values were calculated by Dr. T. Takemura (personal communication) following the methods in Takemura et al. (2005). Figure 13a shows a land-ocean contrast of the effective radius of cloud droplets that is often retrieved from NOAA/AVHRR (Advanced Very High Resolution Radiometer) data (Nakajima and Nakajima, 1995; Kawamoto, 2001). 

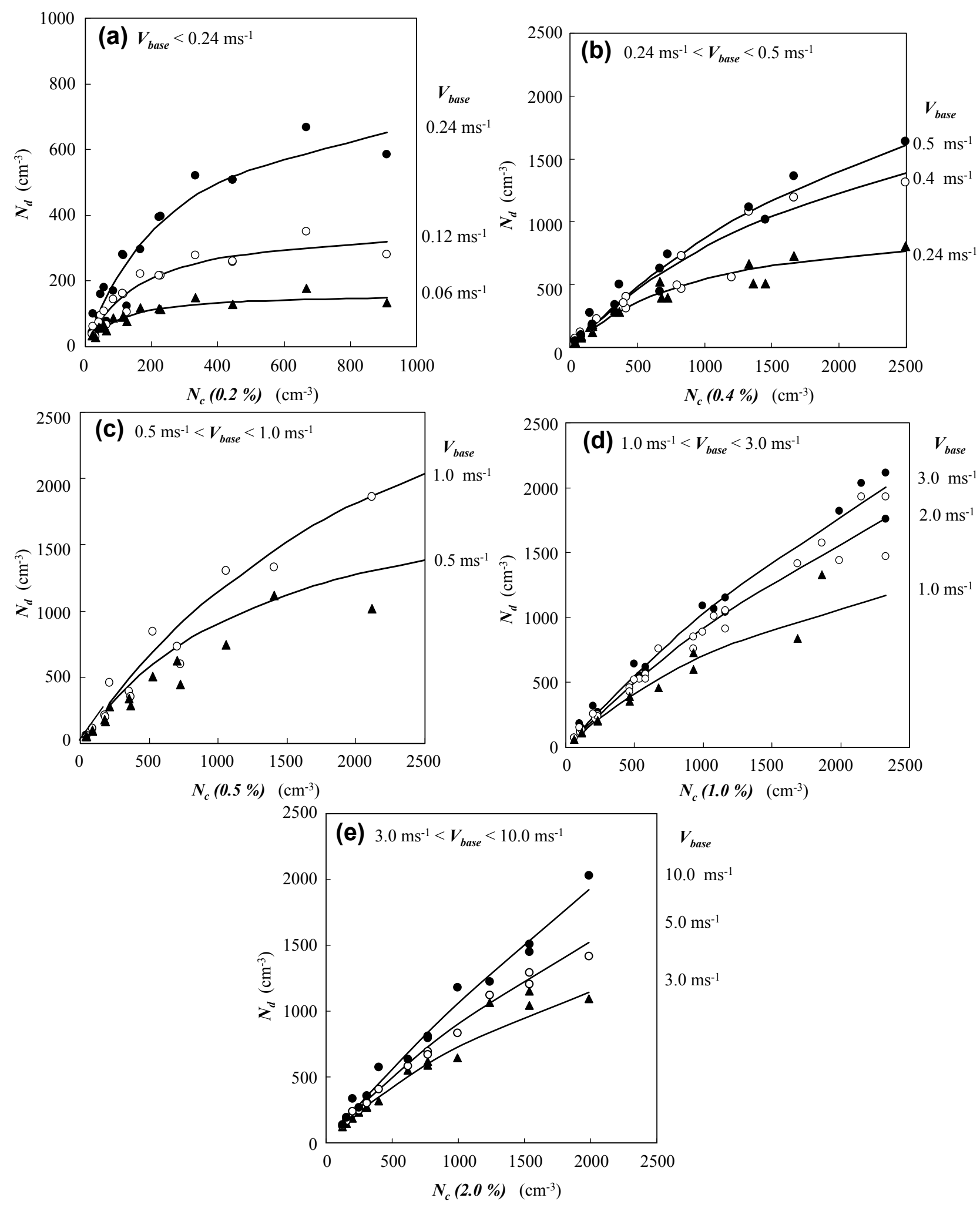

Fig. 12. Relationship between the number of cloud droplets $\left(N_{d}\right)$ and the number of $\operatorname{CCN} N_{c}(S)$ that can be activated at fixed supersaturation $S \%$. The results of the numerical simulations using the cloud microphysical parcel model are shown by marks; approximations using Eq. (1)

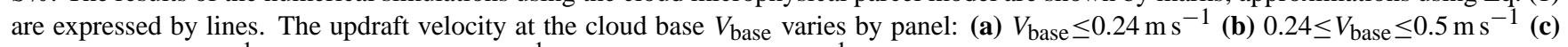
$0.5 \leq V_{\text {base }} \leq 1.0 \mathrm{~m} \mathrm{~s}^{-1}$ (d) $1.0 \leq V_{\text {base }} \leq 3.0 \mathrm{~m} \mathrm{~s}^{-1}$ (e) $3.0 \leq V_{\text {base }} \leq 10.0 \mathrm{~m} \mathrm{~s}^{-1}$. 

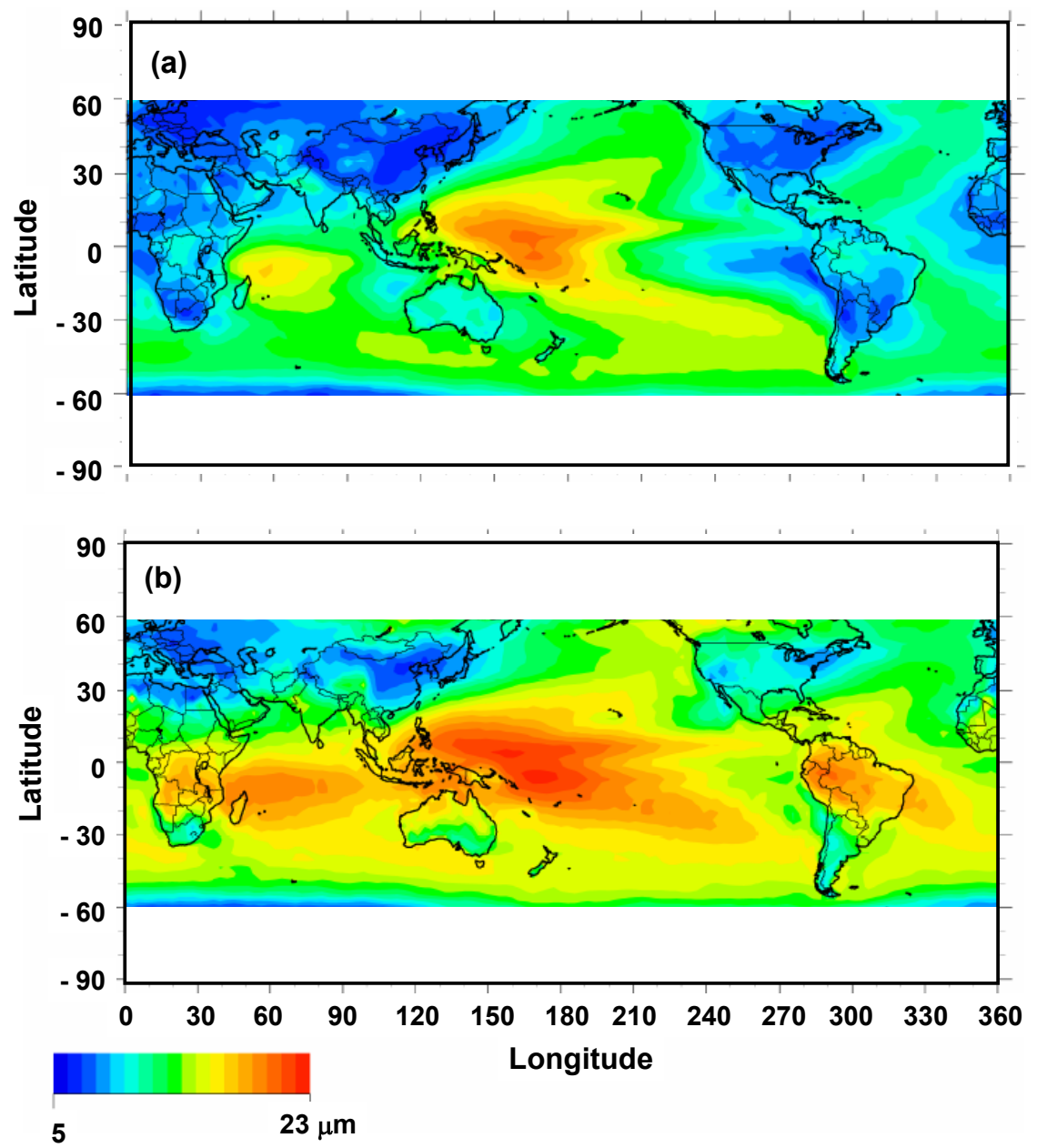

Fig. 13. Calculated annual mean (year 2000) of the effective radius of cloud droplets at the top of clouds that were warmer than $273 \mathrm{~K}$. (a) Organic carbon aerosol particles are considered. (b) Organic carbon aerosol particles are ignored.

To estimate the effect of organic carbon aerosol particles on the effective radius of cloud droplets, Fig. 13b shows the same calculations as in Fig. 13a, but organic carbon particles are neglected. Comparisons of Fig. 13a and b show that considering organic carbon particles leads to decrease in annual mean value of cloud droplet effective radius over South Africa, Australia, and South America. In these regions, concentration of organic carbon particles is not small compared with whole CCN concentration. Therefore, the effect of organic carbon particles on the cloud microstructure is not negligible over South Africa, Australia, and South America.

\subsection{Parameterizations to predict the droplet size distribu- tion}

Both the number of cloud droplets and the shape of the distribution are needed to derive the initial cloud droplet size distribution in the bin model. Gamma distributions have been used in many studies to express the cloud droplet size distri- bution, and they are written as follows:

$$
\begin{aligned}
& n(r)=C r^{\beta} \exp (-D r) d r \\
& C=\frac{N_{d}}{\beta !}\left(\frac{4 \pi}{3 Q}(\beta+3)(\beta+2)(\beta+1) N_{d}\right)^{\frac{\beta+1}{3}} \\
& D=\left(\frac{4 \pi}{3 Q}(\beta+3)(\beta+2)(\beta+1) N_{d}\right)^{\frac{1}{3}} .
\end{aligned}
$$

Here, $n(r)$ is the number density of cloud droplets $\left(\mathrm{cm}^{-4}\right)$, $N_{d}$ is the number concentration of cloud droplets $\left(\mathrm{cm}^{-3}\right)$, and $Q$ is the cloud water $\left(\mathrm{g} \mathrm{cm}^{-3}\right) . \quad \beta$ is an integer ( 2 or 4 in this study). When we can clearly distinguish cloud droplets from non-activated wet $\mathrm{CCN}$ and adjusted cloud water reaches the critical value, the gamma distribution is assigned to the bin as the initial cloud droplet size distribution. 

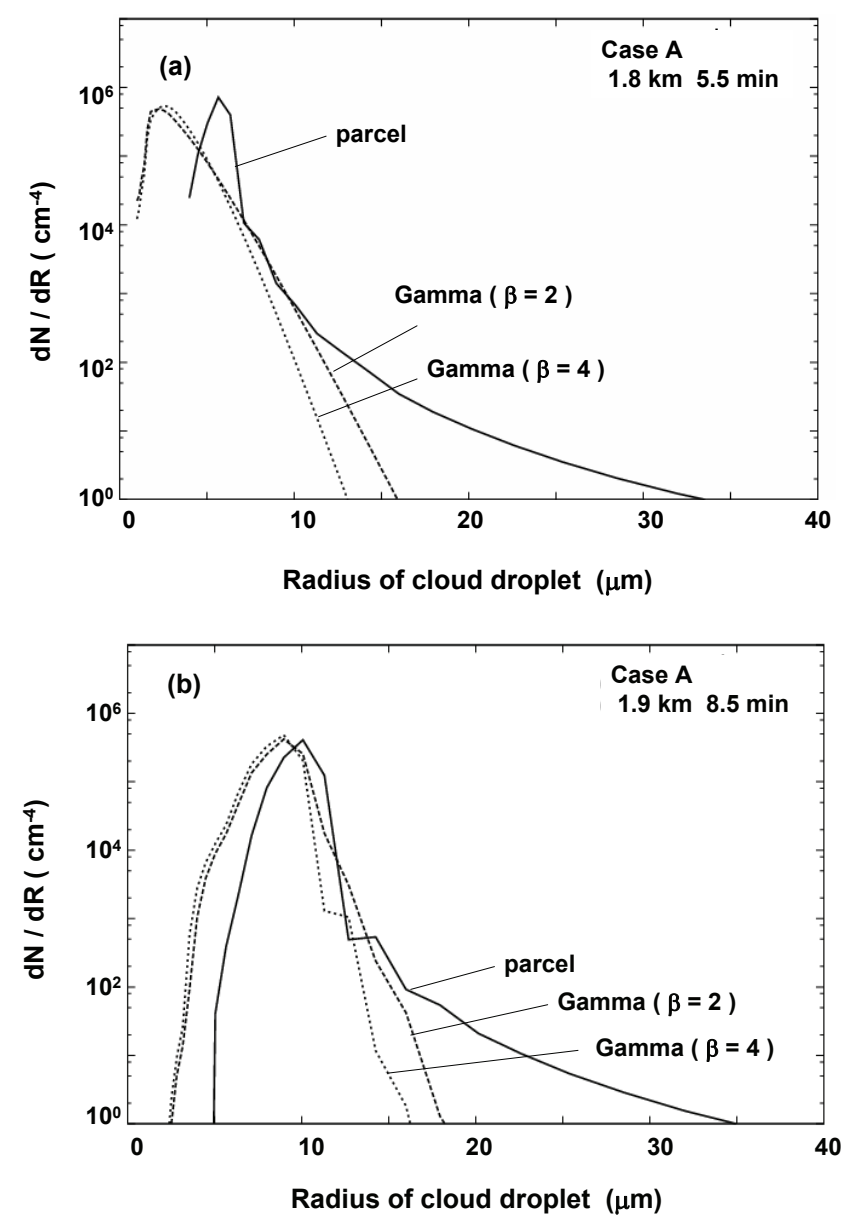

Fig. 14. Cloud droplet size distributions estimated using the parcel model and parameterized using Eqs. (3) and (4). CCN of case A in Fig. 2 are used here. (a) At the cloud base $(1.775 \mathrm{~km})$, at the cloud center, at $5.5 \mathrm{~min}$. Concentrations of cloud droplets in the parcel model case and the parameterization using Eq. (3) case are $103 \mathrm{~cm}^{-3}$ and $116 \mathrm{~cm}^{-3}$, respectively. (b) At a higher level $(1.925 \mathrm{~km})$, at the center of the cloud, at $8.5 \mathrm{~min}$.

\section{Verification of parameterizations of number and size distribution of cloud droplets to create the initial cloud droplet size distribution for bin model}

The hybrid cloud microphysical model described in Sect. 2 is used as truth to verify the parameterizations in Sect. 4. The new model uses the parameterizations instead of the parcel model. Parameterization verification is achieved by comparing the results from the new model using both the parameterizations and bin method, with the results from the model using the hybrid cloud microphysical model that uses both a parcel model and bin method.

The procedure for using parameterizations to predict initial cloud droplet size distribution for the bin model instead of the parcel model is as follows:
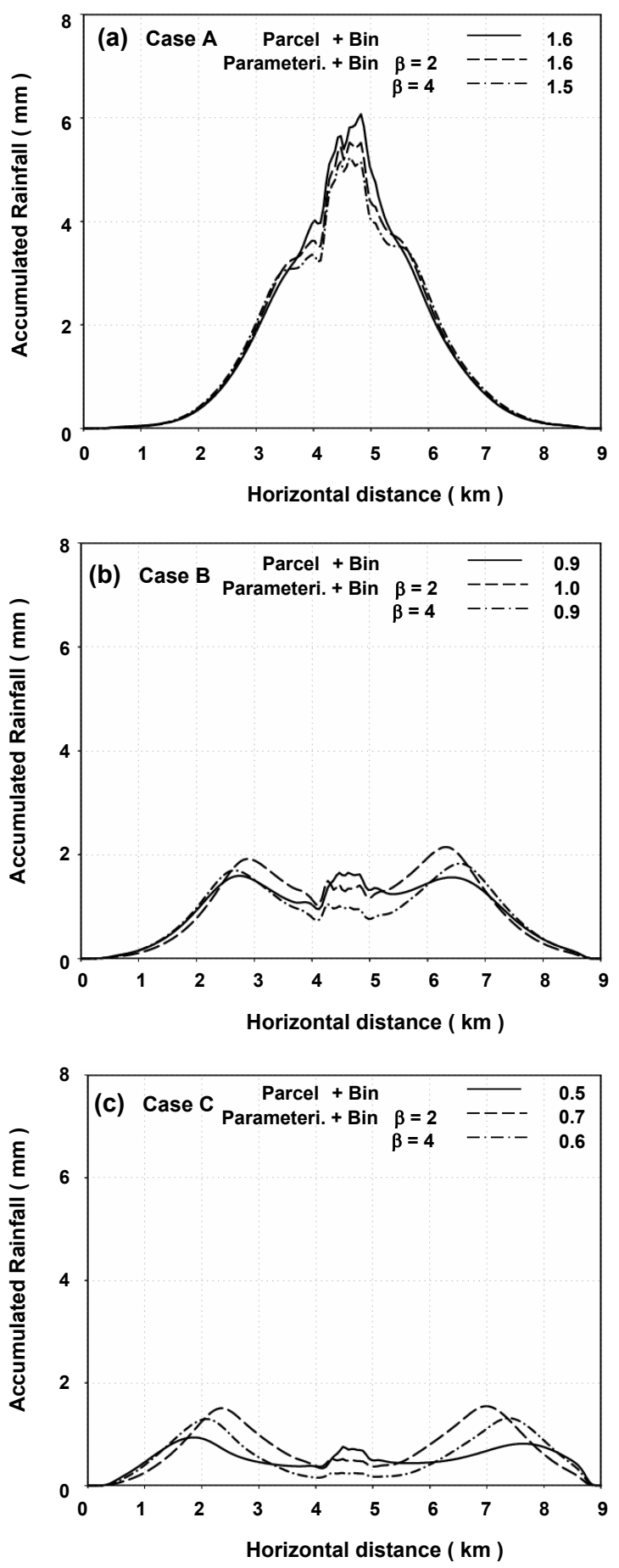

Fig. 15. Accumulated rainfall at $50 \mathrm{~min}$. (a) $\mathrm{CCN}$ from case $\mathrm{A}$ in Fig. 2. Values averaged in the domain for cases using the parcel model and cases using parameterizations with $\beta=2$ and $\beta=4$ are $1.6 \mathrm{~mm}, 1.6 \mathrm{~mm}$, and $1.5 \mathrm{~mm}$, respectively. (b) As in (a), but for $\mathrm{CCN}$ from case B in Fig. 2. Averaged values are $0.9 \mathrm{~mm}, 1.0 \mathrm{~mm}$, and $0.9 \mathrm{~mm}$, respectively. (c) As in (a), but for $\mathrm{CCN}$ from case $\mathrm{C}$ in Fig. 2. Averaged values are $0.5 \mathrm{~mm}, 0.7 \mathrm{~mm}$, and $0.6 \mathrm{~mm}$, respectively. 

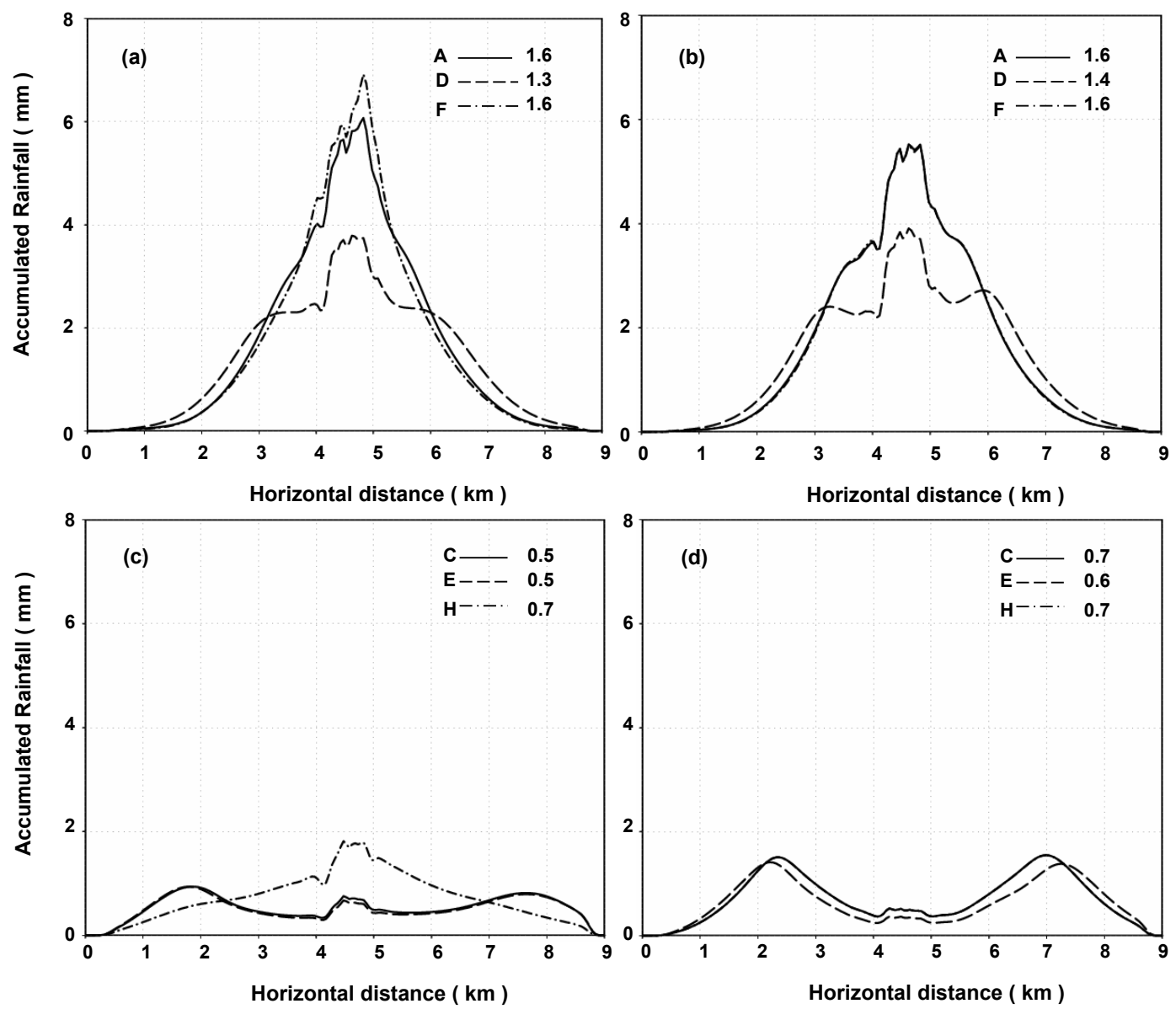

Fig. 16. Accumulated rainfall at 50 min. (a) Results using parcel model for cases A, D, and F. Values averaged in the domain are $1.6 \mathrm{~mm}$, $1.3 \mathrm{~mm}$, and $1.6 \mathrm{~mm}$, respectively. (b) Results using parameterizations in cases A, D, and F. Values averaged in the domain are $1.6 \mathrm{~mm}$, $1.4 \mathrm{~mm}$, and $1.6 \mathrm{~mm}$, respectively. (c) Results using parcel model in cases $\mathrm{C}$, E, and $\mathrm{H}$. Averaged values in the domain are $0.5 \mathrm{~mm}, 0.5 \mathrm{~mm}$, and $0.7 \mathrm{~mm}$, respectively. (d) Results using parameterizations in cases C, E, and H. Averaged values in the domain are $0.7 \mathrm{~mm}, 0.6 \mathrm{~mm}$, and $0.7 \mathrm{~mm}$, respectively.

1. When the condensed cloud water determined by adjusting the supersaturation at a grid point reaches $1.5 \mathrm{e}-5$ $\left(\mathrm{g} \mathrm{g}^{-1}\right), N_{d}$ is derived by Eq. (3). This threshold was derived from many trials that tested whether cloud droplets could be clearly distinguished from non-activated CCN.

2. Using $N_{d}$ and the adjusted condensed cloud water $Q$, the cloud droplet size distribution $n(r)$ (Eq. 4) is derived.

3. The number and total mass of droplets included in each bin are calculated by integrating Eq. (4).

Figure 14a shows the cloud droplet size distributions derived explicitly by the parcel model and approximated by Eqs. (3) and (4) for case A. Cloud droplet size distributions derived from the parameterization with a Gamma distribution are wider than those derived using the parcel model, and the large cloud droplets that condense on giant-particle $\mathrm{CCN}$ cannot be described. Differences in the cloud droplet size distribution between the parcel model and the parameterization are smaller at later stages and at higher levels in the cloud (Fig. 14b), except for large droplets condensed on giantparticle CCN. Because the numbers of cloud droplets in both the parcel model and the parameterization are same and the smaller droplets grow faster, the differences become smaller. However the lack of large cloud droplets condensed on giantparticle $\mathrm{CCN}$ in the cloud droplet size distribution derived from parameterization is not solved even in this stage. It is the restriction of this parameterization.

Figures $15 \mathrm{a}-\mathrm{c}$ shows the accumulated surface rainfall at 50 min for cases A, B, and C, respectively. Differences between the results from the parcel model and those from the parameterizations are not large (mean values in the domain are also shown in Fig. 15). Parameterizations can express differences in rainfall amounts caused by differences in the number of small CCN. Using 4 as $\beta$ offers little improvement over 2 , so 2 is used from now on. 
The effect of adding large or giant $\mathrm{CCN}$ was tested in cases for which large $\mathrm{CCN}$ or giant $\mathrm{CCN}$ were increased fivefold over case A (clean maritime case) or C (small-particle rich case). Figure 16a shows accumulated surface rainfall at 50 min for case A and the case with high concentrations of large CCN (case D) or giant CCN (case F) from the hybrid cloud model that uses the parcel method and two-moment bin method. Figure $16 \mathrm{~b}$ is the same as Fig. 16a but shows the results from the cloud model that uses parameterization and the two-moment bin method. Adding large $\mathrm{CCN}$ reduces the rainfall amounts; adding giant $\mathrm{CCN}$ has little effect on the rainfall amounts. Comparisons of Figs. 16a and $b$ show that the parameterization predicts the effects of adding large or giant $\mathrm{CCN}$.

Figures $16 \mathrm{c}$ and $d$ are similar to Figs. 16a and b, but large $\mathrm{CCN}$ (case E) or giant $\mathrm{CCN}$ (case $\mathrm{H}$ ) are added to case C (small-particle rich case). As noted in Sect. 3.2, adding large $\mathrm{CCN}$ does not affect the rainfall amounts for this case. Adding giant $\mathrm{CCN}$ causes an increase in rainfall over the small-particle rich case (Fig. 16c for the hybrid cloud microphysical model) as shown in Sect. 3.3. In contrast, the method using parameterizations and the twomoment bin cannot model the effect of adding giant $\mathrm{CCN}$ (Fig. 16d). The parameterizations use the number of CCN, so differences in the number of giant $\mathrm{CCN}$ cannot be reflected in the initial cloud droplet size distribution of the bin model. However, the effect of giant $\mathrm{CCN}$ on warm rain is not so large for usual cases (cases A, B, and C, for example), as discussed in Sect. 3.3. Therefore these parameterizations may be useful for estimating the effect of $\mathrm{CCN}$ on warm rain in non-hydrostatic 3-D cloud models except for cases in which giant-particle $\mathrm{CCN}$ has large effect on precipitation. In these cases the hybrid cloud microphysical model that uses both parcel model and bin method is useful.

\section{Conclusions}

A hybrid cloud microphysical model was developed that combines Lagrangian and Eulerian frameworks. The model can estimate the effect of $\mathrm{CCN}$ on cloud microstructure. The effect of CCN on warm cloud rainfall was studied using this microphysical model and a simple two-dimensional cloud model, and the following conclusions were reached:

1. The number of small-particle $\mathrm{CCN}$ has a large impact on the amount of rainfall. Larger numbers of smallparticle CCN cause a smaller mode radius of cloud droplets at the cloud base and lead to lighter rainfall. Adding small-particle $\mathrm{CCN}$ reduces both the amount of rainfall and the fall velocity of raindrops, which affects the rainfall area.

2. Adding large-particle CCN leads to a decrease in the mode radius of cloud droplets at the cloud base when there are small numbers of small CCN. On the other hand, when there are large numbers of small-particle $\mathrm{CCN}$, adding large-particle $\mathrm{CCN}$ leads to an increase in large cloud droplets at the cloud base. Adding largeparticle CCN leads to a decrease in the amount of rainfall when there are small numbers of small-particle $\mathrm{CCN}$; it does not affect the amount of rainfall when there are large numbers of small $\mathrm{CCN}$. When there are few CCN, rainwater is produced from condensation onto small-particle $\mathrm{CCN}$ but not from condensation onto large-particle $\mathrm{CCN}$.

3. When there are small numbers of small-particle $\mathrm{CCN}$, adding giant-particle $\mathrm{CCN}$ leads to a slight decrease in rainfall, which suggests that almost all rain water is produced by condensation onto small-particle $\mathrm{CCN}$. On the other hand, when there are large numbers of small-particle $\mathrm{CCN}$, adding giant-particle $\mathrm{CCN}$ leads to a modest increase in the amount of rainfall, which suggests that rain water is produced mainly from condensation onto giant-particle $\mathrm{CCN}$ and cloud droplets caught by large droplets condensed on giant-particle $\mathrm{CCN}$.

4. The influence of $\mathrm{CCN}$ on the rain formation rate depends not only on the amount and size of additional $\mathrm{CCN}$ but also on the environment in terms of the degree of pollution.

5. Rainfall calculated by a bulk microphysical model using Kessler's parameterization can be tuned by changing the coefficients. However, the relationship between the coefficients and CCN properties is unclear. Furthermore, the bulk model does not express the proper fall velocities of raindrops that are distributed over a wide velocity range. A high-resolution cloud model therefore needs a cloud microphysical model that uses a bin method.

Dynamical factors primarily determine the precipitation properties, nevertheless aerosol properties as $\mathrm{CCN}$ can modify the precipitation. Therefore, the effect of $\mathrm{CCN}$ on the precipitation is investigated in this study. The kinematic framework in this study is so simple that a change in cloud microstructure cannot affect cloud dynamics. Therefore, a quantitatively accurate estimate of the effect of $\mathrm{CCN}$ on warm rain cannot be studied here. However, the basic role of $\mathrm{CCN}$ in warm rain production can be estimated using the hybrid cloud microphysical model. The effect of CCN on warm rain can be estimated quantitatively when the hybrid cloud microphysical model is incorporated into a threedimensional cloud dynamical model. In addition, the model can be used to verify and improve the microphysical bulk model.

In the dynamical framework used in this study, the magnitude, vertical structure, width and tilt of the flow through the central updraft are prescribed using simple analytical functions. Therefore, latent heat does not induce turbulence in this study unfortunately. We are installing our cloud microphysical model into a three-dimensional non-hydrostatic 
cloud model to estimate the effect of $\mathrm{CCN}$ on cloud dynamical field.

Parameterizations to predict the initial cloud droplet size distribution for the bin model were developed. The results from a cloud model using these parameterizations and a twomoment bin model were compared to results from a hybrid cloud microphysical model that combines Lagrangian and Eulerian frameworks. Replacing the parcel model with the parameterizations developed in this study saves computing time at the cost of a small degree of error. A cloud model that includes the parameterizations and a two-moment bin model estimates the effects of $\mathrm{CCN}$ on cloud microstructure with sufficient accuracy. These parameterizations use only the number of $\mathrm{CCN}$ that can be activated under a certain supersaturation $(0.2-2.0 \%)$. Thus, the effect of giantparticle $\mathrm{CCN}$ on warm rain precipitation cannot be estimated. However, the effect of giant-particle $\mathrm{CCN}$ is not large compared to the effects of small and large-particle CCN. If the effect of seeding giant-particle $\mathrm{CCN}$ must be estimated, a combination of two cloud-droplet size distributions can be used as the initial cloud droplet size distribution for the bin model, although only one gamma distribution was used in this study, or the hybrid cloud microphysical model developed in Sect. 2 in this study is useful. The developed parameterizations and the two-moment bin method are now running in a three-dimensional non-hydrostatic cloud model, CReSS (Tsuboki and Sakakibara, 2002). The parameterizations to predict the number of cloud droplets can be also applied to a GCM. GCM simulations that include an aerosol transport model and the developed parameterizations show that the effect of organic carbon particles on the cloud microstructure is not negligible over South Africa, Australia, and South America.

Acknowledgements. The authors sincerely thank T. Takemura of Kyushu University, who incorporated the parameterizations developed in this study into the global model CCSR/NIES/FRCGCAGCM equipped with the aerosol transport model SPRINTARS (Takemura et al., 2000, 2002). We wish to thank K. Kawamura and M. Mochida of Institute of Low Temperature Science Hokkaido University, for helpful discussions about organic carbon aerosol particles. We also wish to acknowledge useful discussions with $\mathrm{M}$. Yamasaki, K. Nakamura, and H. Iwabuchi of Frontier Research Center for Global Change (FRCGC/JAMSTEC).

Edited by: U. Lohmann

\section{References}

Albrecht, B. A., Bretherton, C. S., Johnson, D., Scubert, W. H., and Frisch, A. S.: The Atlantic stratocumulus transition experiment - ASTEX, Bull. Am. Meteorol. Soc., 76, 889-904, 1995.

Andreae, M. O., Rosenfeld, D., Artaxo, P., Costa, A. A., Frank, G. P., Longo, K. M., and Silva-Dias, M. A. F.: Smoking rain clouds over the Amazon, Science, 303, 1337-1342, 2004.

Bott, A.: A flux method for the numerical solution of the stochastic collection equation, J. Atmos. Sci., 55, 2284-2293, 1998.

Chen, J. -P. and Lamb, D.: Simulation of cloud microphysics and chemical processes using a multicomponent framework. Part I Description of the microphysical model, J. Atmos. Sci. 51, 26132630, 1994.

Chen, J. -P. and Lamb, D.: Simulation of cloud microphysics and chemical processes using a multicomponent framework. Part II Microphysical evolution of a wintertime orographic cloud, J. Atmos. Sci., 56, 2293-2312, 1999.

Chen, J.-P. and Liu, S.-T.: Physically based two-moment bulkwater parametrization for warm-cloud microphysics, Q. J. R. Meteorol. Soc., 130, 51-78, 2004.

Chuang, P. Y., Charlson, R. J., and Seinfeld, J. H.: Kinetic limitations on droplet formation in clouds, Nature, 390, 11, 595-596, 1997.

Clark, T. L.: Numerical modeling of the dynamics and microphysics of warm cumulus convection, J. Atmos. Sci., 30, 857-878, 1973.

Cooper, W. A., Bruintjes, R. T., and Mather, G. K.: Calculating pertaining to hygrospic seeding with flares, J. Appl. Meteor., 36, 1449-1469, 1997.

Cotton, W. R. and Anthes, R. A.: Storm and Cloud Dynamics (Chapter 4), Academic Press, 880pp., 1989.

Cotton, W. R., Pielke, R. A. Sr., Walco, R. L., Liston G. E., Tremback, C. J., Jiang, H., McAnelly, R. L., Harringto, J. Y., Nicholls, M. E., Carrio, G. G., and McFadde, J. P.: RAMS 2001: Current status and future directions, Meteorol. Atmos. Phys., 82, 5-29, 2003.

Feingold, G., Cotton, W. R., Kreidenwei, S. M., and Davis, J. T.: The impact of giant cloud condensation nuclei on drizzle formation in stratocumulus: Implications for cloud radiative properties, J. Atmos. Sci., 56, 15, 4100-4117, 1999.

Fitzgerald, J. W.: Effect of aerosol composition on cloud droplets size distribution: a numerical study, J. Atmos. Sci., 31, 13581367, 1974.

Ghan, S., Easter, R., Hudson, J., and Breon, F. M.: Evaluation of aerosol indirect radiative forcing in MIRAGE, J. Geophys. Res., 106(D6), 5317-5334, 2001.

Givati, A. and Rosenfeld, D.: Quantifying precipitation suppression due to air pollution, J. Appl. Meteor., 43, 1038-1056, 2004.

Hall, W. D.: A detailed microphysical model within a twodimensional dynamic framework: Model description and preliminary results, J. Atmos. Sci., 37, 2486-2507, 1980.

Harshvardhan, S., Schwartz, E., Benkovitz, C. M., and Guo, G.: Aerosol influence on cloud microphysics examined by satellite measurements and chemical transport modeling, J. Atmos. Sci., 59, 714-725, 2002.

Kawamoto, K., Nakajima, T., and Nakajima, T. Y.: A global determination of cloud microphysics with AVHRR remote sensing, J. Climate, 14, 2054-2068, 2001. 
Khain, A., Pokrovsky, A., and Sednev, I.: Some effects of cloudaerosol interaction on cloud microphysics structure and precipitation formation: numerical experiments with a spectral microphysics cloud ensemble model, Atmos. Res., 52, 195-220, 1999.

Khairoutdinov, M. F. and Kogan, Y. L.: A large eddy simulation model with explicit microphysics: Validation against aircraft observations of a stratocumulus-topped boundary layer, J. Atmos. Sci., 56, 1, 2115-2131, 1999.

Kuba, N. and Takeda T.: Numerical study of the effect of CCN on the size distribution of cloud droplets. Part II. Formation of large droplets, J. Meteorol. Soc. Japan, 61, 3, 375-387, 1983.

Kuba, N. and Iwabuchi, H.: Revised parameterization to predict cloud droplet concentration and a retrieval method to predict CCN concentration, Supplement, J. Meteorol. Soc. Japan, 81, 1485-1487, 2003.

Kuba, N., Iwabuchi, H., Maruyama, K., Hayasaka, T., Takeda, T., and Fujiyoshi, Y.: Parameterization of the effect of cloud condensation nuclei on the optical properties of a non-precipitating water layer cloud, J. Meteorol. Soc. Japan, 81, 393-414, 2003.

Lohmann, U., Feichter, J., Chuang, C. C., and Penner, J. E.: Prediction of the number of cloud droplets in the ECHAM GCM, J. Goephys. Res., 104, 9169-9198, 1999.

Mordy, W.: Computation of the growth by condensation of a population of cloud droplets, Tellus, XI, 16-44, 1959.

Nakajima, T. Y. and Nakajima, T.: Wide-area determination of cloud microphysical properties from NOAA AVHRR measurements for FIRE and ASTEX regions, J. Atmos. Sci., 52, 40434095, 1995.

Numaguti, A.: Dynamics and energy balance of the Hadley circulation and the tropical precipitation zones: Significance of the distribution of evaporation, J. Atmos. Sci., 50, 1874-1887, 1993.

Numaguti, A., Takahashi, M., Nakajima, T., and Sumi, A.: Development of an atmospheric general circulation model, in: Reports of a New Program for Creative Basic Research Studies, Studies of Global Environment Change with Special Reference to Asia and Pacific Regions, Rep., I-3, 1-27, CCSR, Tokyo, 1995.

Reisin, T. G., Levin, Z., and Tzivion, S.: Rain production in convective clouds as simulated in an axisymmetric model with detailed microphysics. Part I: Description of model, J. Atmos. Sci., 53, 3, 497-519, 1996.

Rosenfeld, D.: TRMM observed first direct evidence of smoke from forest fires inhibiting rainfall, Geophys. Res., Lett., 26, 31053108, 1999.

Rosenfeld, D.: Suppression of rain and snow by urban and industrial air pollution, Science, 287, 1973-1976, 2000.
Saleeby, S. M. and Cotton, W.: A large-droplet mode and prognostic number concentration of cloud droplets in the Colorado State University Regional Atmospheric Modeling System (RAMS). Part I: Module descriptions and supercell test simulations, J. Appl. Meteor., 43, 182-195, 2004.

Smolarkiewicz, P. K.: A fully multidimensional positive definite advection transport algorithm with small implicit diffusion, J. Comput. Phys., 54, 325-362, 1984.

Szumowski, M. J., Grabowski, W. W., and Ochs III, H. T.: Simple two-dimensional kinematic framework designed to test warm rain microphysical models, Atmos. Res., 45, 299-326, 1998.

Takahashi, T.: Hail in an axisymmetric cloud model, J. Atmos. Sci., 33, 1579-1601, 1976.

Takeda, T. and Kuba, N.: Numerical study of the effect of CCN on the size distribution of cloud droplets. Part I. Cloud droplets in the stage of condensation growth, J. Meteor. Soc. Japan, 60, 4, 978-993, 1982.

Takemura, T., Okamoto, H., Maruyama, Y., Numaguti, A., Higurashi, A., and Nakajima, T.: Global three-dimensional simulation of aerosol optical thickness distribution of various origins, J. Geophys. Res., 105, 17 853-17 873, 2000.

Takemura, T., Nakajima, T., Dubovik, O., Holben, B. N., and Kinne, S.: Single-scattering albedo and radiative forcing of various aerosol species with a global three-dimensional model, J. Climate, 15, 333-352, 2002.

Takemura, T., Nozawa, T., Emori, S., Nakajima, T. Y., and Nakajima, T.: Simulation of climate response to aerosol direct and indirect effects with aerosol transport-radiation model, J. Geophys. Res., 110, D02202, doi:10.1029/2004JD005029, 2005.

Tsuboki, K. and Sakakibara, A.: Large-scale parallel computing of Cloud Resolving Storm Simulator, High Performance Computing, Springer, edited by: Zima, H. P., Joe, K., Sato, M., Seo, Y., and Shimasaki, M., 243-259, 2002.

Twomey, S.: The nuclei of natural cloud formation, Part II: The supersaturation in natural clouds and the variation of cloud droplet concentration, Geofis. Pura. Appl., 43, 243-249, 1959.

Twomey, S.: Pollution and the planetary albedo, Atmos. Environ., 8, 1251-1256, 1974.

Twomey, S and Squires, P.: The influence of cloud nucleus population on the microstructure and stability of convective clouds, Tellus, XI, 4, 408-411, 1959.

Twomey, S. and Waner, J.: Comparison of measurements of cloud droplets and cloud nuclei, J. Atmos. Sci., 24, 702-703, 1967.

Yun, S. S. and Hudson, J.: Maritime/continental microphysical contrasts in stratus, Tellus, 54B, 61-73, 2002. 